\title{
Politische Umwälzungen unter den Slowenen vom Ende des sechsten Jahrhunderts bis zur Mitte des neunten.
}

Von

\section{Ludmil Hauptmann.}

\section{Die awarische Herrschaft.}

Als sich die Awaren in der ungarischen Tiefebene niedergelassen hatten, standen ihren Raubzügen nach Westen urrd Südwesten außer der Donau zwei Straßen offen: die Drau und mit ihr sich kreuzend, der uralte Weg über die mittlere Mur und Sawe an den Isonzo ${ }^{1}$ ). Da die Slowenen gerade an diesen beiden Heerstraßen saßen, so war ihr Los die awarische Knechtschaft. Schon 596 kämpften sie daher in engster Gemeinschaft mit den Awaren gegen die Bayern ${ }^{2}$ ) und auch noch 610, als der Chagan durch ihr Land nach Oberitalien zog, dachten sie an keinen Widerstand gegen ihre Herrn ${ }^{3}$ ).

Schmid allerdings will, wenigstens für Oberkrain, die Herrschaft der Awaren nicht gelten lassen. Aus einem Waffenfund im Gräberfelde von Krainburg schließt er, daß dort einst eine langobardische Besatzung gelegen habe und somit Oberkrain den Langobarden gehört haben müsse. Das stimme auch sehr gut zu dem, was sich aus den schriftlichen Quellen über dieses Land ergebe. Denn da Krain seit

1) Jung, Römer und Romanen in den Donauländern S. 110. - Huber, Geschichte Österreichs I S. 19.

2) Pauli Diaconi Hist. Langob. IVc 10 (M.G. SS. rer. Langob. S. 120).

9) Ebenda IVc 37. 
dem dritten Jahrhundert zu Italien gerechnet worden sei, so könne der „breite und ebene Zugang “ Italiens zu Pannonien, von dem Paulus Diaconus spricht, nur an der heute steirisch-krainischen Grenze, in der Mulde zwischen Gurkfeld und Rann an der Sawe gewesen sein. Bis dahin habe der Langobardenstaat gereicht. Krainburg wäre dann eine Grenzfeste gewesen, bestimmt, awarischen Horden den Weg nach Italien zu verlegen. Paulus Diacouus, meint Schmid, erzähle sogar, wann die Langobarden ihre Macht bis an die Sawe ausgedehnt hätten. Denn unbedenklich könne man das slawische Zellia, das Taso und Caco von Friaul nach dem großen Awarensturm von 610 eroberten, auf Oberkrain beziehen ${ }^{1}$ ). Allein Schmids Auffassung läßt sich bündig widerlegen: zunächst durch seinen eigenen Kronzeugen, Paulus Diaconus, der die Slawenkriege durchaus nicht als Aufstände unbotmäßiger Untertanen, sondern als Einfälle feindlicher Nachbarn behandelt ${ }^{2}$ ) und dann durch die Worte des ravennatischen Kosmographen, der sagt, daß die Ausläufer der Alpen, die erst ,bei Fianona an der Adria endeten", die Grenze ,zwischen Karantanien und Italien, zwischen Krain und Italien" gebildet hätten ${ }^{3}$ ). Die Gegenüberstellung von Krain und Italien und die Grenze, die man nach dieser Ausdrucksweise von den Kalkalpen Kärnten-Krains zu den Karststufen Istriens zu ziehen hat, zeigt deutlich genug, daß sich das italische Langobardenreich nur bis an den Westsaum Krains erstreckt haben kann. Wäre Krain langobardisch, die Kämple der Slawen gegen die Langobarden daher Empörungen eines unterworfenen Volkes gewesen, so hätten sich auch die Zusammenstöße vor allem in Krain und nicht regelmäßig schon jenseits der Karsthöhen in Friaul abgespielt4). Selbst die langobardische Sage liefert einen Beweis gegen Schmid. Sie berichtet, Alboin habe, an der italisch-pannonischen Grenze angelangt, einen hohen Berg bestiegen und zu seinen Füßen Italien gesehen 5). Hätten sich, wie Schmid es will, Italien und Pannonien wirklich an der Sawe, etwa zwischen Gurkfeld und Rann, berührt, so hätte Alboin wohl vergeblich einen Berg mit solcher Rundsicht gesucht. Reichte aber Pannonien bis an den Karstrand Krains, so gab

1) Schmid, Das Gräberfeld von Krainburg (Mitteilungen des Musealvereins für Krain XVIII S. 82 ff.); ders., Die Reihengräber von Krainburg (Jahrbuch für Altertumskunde I. S. 55 ff.).

2) Pauli diaconi Hist. Langob. IVc 38, Vc $22 \mathrm{f}$, VIc 24, c 45.

3) Anonymi Ravennatis Cosmographia (hgg. von Pinder u. Parthey) IVc 37.

4) Mit Ausnahme des Kampfes von etwa 738: Pauli diaconi Hist. Lang. VIc 52.

5) Ebenda II c 8 . 
es der Gipfel genug, von denen sich Alboin den Blick auf Italien verschaffen konnte. Den ,ebenen und weiten Zugang von Pannonien nach Italien" braucht man deshalb nicht preiszugeben; im Gegenteil, man findet ihn vielmehr gerade am Westrande Krains, am Abhang des Birnbaumerwaldes, im Wippachtali). Damit entfällt aber der leiseste Anlaß, „Zellia“, das Taso und Caco erobert hatten, mit Oberkrain in Verbindung zu bringen. Strakosch-GraBmann hat ohnehin für den vielumstrittenen Namen eine befriedigende Erklärung geboten, indem er Zellia dem heutigen Cegle bei Kormons im Görzischen gleichsetzte 2). Das Tiefland am Isonzo mögen Taso und Caco unterworfen haben, vielleicht zur Zeit Samos, als Dagobert gegen dessen Slawen auch die Langobarden aufbot ${ }^{3}$ ); Oberkrain aber war nie langobardisch. Wollte man die Waffenfunde von Krainburg unbedingt mit einer langobardischen Besatzung in Zusammenhang bringen, so dürfte man höchstens an die Jahre 796-828 denken, in denen Krain zur Mark Friaul gehörte ${ }^{4}$ ) und sehr gut zur Sicherung des Gewonnenen mit kleinen Besatzungen belegt worden sein kann. Wäre diese Deutung aber zeitlich wegen des Stiles der gefundenen Waffen unmöglich, so müßte man die Funde Awaren oder Slowenen zuweisen, für Langobarden oder überhaupt germanische Krieger wäre vor Karl dem Großen im slowenischen Krain kein Platz. Aus den Gräberfunden läßt sich daher gegen den Bestand der Awarenherrschaft in Krain nichts einwenden. Nur über die Art ihrer Herrschaft könnte man streiten.

Man behauptet nämlich gelegentlich, die Slowenen seien den Awaren nur lose verbunden gewesen, und beruft sich zum Beweise dessen darauf, daß Paulus Diaconus von Feldzügen der Slowenen berichtet, ohne einer Mitwirkung der Awaren zu gedenken. Indem man daraus folgert, sie hätten solche Kriege auf eigene Faust geführt, ist man wohl gar bereit, die Slowenen mehr als Bundesgenossen denn als Knechte der Awaren zu betrachten o). Allein man übersieht dabei, daß die Schriftsteller jener Tage sehr oft Awaren und Slawen nicht unterschieden und gelegentlich nur die einen nannten, obwohl sie eigentlich beide meinten ${ }^{6}$ ). Wer weiß, ob nicht auch Paulus Diaconus in den oben berührten Fällen über den slowenischen Massen der

1) Kos, Gradivo za zgodovino Slovencev I S. 66 n. 4.

2) Strakosch-Grassmann, Geschichte der Deutschen I. S. 319.

s) Vgl. unten S. 19.

4) Vgl, unten S. 35.

s) Kos, Gradivo za zgodovino Slovencev I S. XXXVII.

в) Niederle, Slovanské starožitnosti II S. $209 \mathrm{ff}$. 
awarischen Führer vergessen hatte! Will man jedoch diese Möglichkeit nicht zugeben, so findet man noch eine zweite Erklärung in Paulus Diaconus selbst, der erzählt, 603 hätten die Slowenen mit den Langobarden zusammen Cremona belagert, - weil sie der Chagan dem König Agilulf zu Hilfe geschickt1). Denkt man sich diese Begründnng weg, so hörte man wieder nichts vou den Awaren und der Rest (ler Nachricht wäre auf einmal ein Zeugnis für die Bewegungsfreiheit und Unabhängigkeit der Slowenen, obwohl, wie man sieht, die Meldung in Wirklichkeit für ihren Knechtesgehorsam spricht.

Dal3 die Herrschaft der Awaren gar nicht milde sein konnte, lag am Wesen ihres Staates. Sie waren zu rohe Barbaren, als daß sie verstanden hätten, ihrem Reiche durch irgend eine Art von Verwaltung innere Festigkeit zu verleihen. Ihr einziger Grundsatz war Willkür. Nach viehischem Gelüst schaltete der Aware in Hause und in der Familie des Slawen, bei dem er mit seinen Herden überwinterte, ohne Bedenken trieb er die Unterworfenen Schar um Schar in die Speere der Feinde, während er selbst sich schlau im Hintertreffen hielt 2). Nur dumpfe Ergebung in ein unabänderlich scheinendes Schicksal konnte die Unterjochten solche Zustände ertragen lehren. Alles kam daher für die Awaren darauf an, diese Willenlosigkeit planmäßig zu züchten. Ein Mittal hiefür lassen die Ergebnisse mundartlicher Forschungen in Oberitalien erkennen.

Im äußersten Nordosten Friauls, wo die wilden Kalkmassen der Julischen Alpen auf italienischen Boden übergreifen, liegt das Tal der Resia, eine Welt für sich. Mäclitige Berge, der Monte Kanin und seine Genossen, schnüren es so fest $a b$, dall es nur durch eine enge Schlucht am Unterlaufe der Resia mit der Außenwelt zusammenhängt. An der slowenischen Mundart dieses Tales hat nun Bandouin de Courtenay eine Eigenheit entdeckt, die in keiner indogermanischen Sprache vorkommt: das ist, wie er sagt, die „Harmonie der Vokale“ ${ }^{3}$ ). Sie besteht darin, daß der Selbstlaut der betonten Silbe immer den der unbetonten bestimmt. Infolgedessen dekliniert zum Beispiel der

1) Pauli Diaconi hist. Langob. IV c. 28.

2) Fredegarii Chronicon lib. IV c. 48 MG. SS. rer. Meroving. If S. 144): Winidi befulci Chunis fuerant iam ab antiquito, ut, cum Chuni in exercitu contra gentem qualibet adgrediebant, Chuni pro castra adunatum illorum stabant exercitum, Winidi vero pugnabant: si ad vincendum prevalebant, tunc Chuni predas. capiendum adgrediebant; sin autem Winidi superabantur, Chunorum auxilio fulti virebus resumebant. ... Chuni aemandum annis singulis in Esclavos veniebant, uxores Sclavorum et filias eorum strato sumebant.

s) Baudouin-de.Courtenay, Rezija i Rezijane S. $321 \mathrm{ff}$. 
Resianer statt žena, žene (die Frau): žanà, žoenoè. Da aber diese Erscheinung sonst nur derı turanischen Sprachen eigentümlich ist, so schließt Baudouin mit Recht, daß sich hier slawisches und turanisches Volkstum vermengt haben muß 1 ).

Gerade von den Awar $€ n$ weiß man nun sehr gut, daß sie sich einst auch in Friaul niederlassen wollten. Als sie nämlich um 663 dem Langobardenkönige Grimoald gegen den aufständischen Herzcg Lupus von Friaul zu Hilfe geeilt waren und den Empörer besiegt hatten, weigerten sie sich, Friaul ,je wieder zu räumen“ ${ }^{2}$ ) Zwar machte die Klugheit Grimoalds ihren Plan zu Schanden, aber schon ihr Entschluß allein zeigt, daß sie gewohnt waren, in eroberte Lïnder Besatzungen zu legen. Man hat daher allen Grund, den turanischen Einschlag in der Mundart der Resia so zu erklären, daß vielleicht schon 610, als der Chagan durch seine Siege über die Langobarden ${ }^{3}$ ) den Slowenen Wohnsitze in Friaul erkämpft hatte, oder aber bei einem späteren ähnlichen Anlaß einzelne Horden der Awaren zur Sicherung des Gewonnenen im Lande blieben. Nur war die Zahl ihrer Mitglieder offenbar so klein oder schmolz in den Stürmen späterer Zeiten so arg zusammen, daß der italienische Slowene in seinem Äußern heute nichts von einer Beimisthung awarischen Blutes verrät. Bloß die Sprache und auch die nur in weltfernsten Winkel, in der Resia, - hat die Spuren turanischen Einflusses bewahrt ${ }^{4}$ ).

Was so für Friaul die mundartliche Forschung lehrt, das bestätigt für Kärnten der Ortsname Heunburg oder, wie er in alten Urkunden lautet, Hunenburg ${ }^{5}$ ). Denn wer diese Hunnen gewesen sein mögen, darüber gibt das slowenische Vovbre eindeutig Bescheid, steckt doch darin Ober und das heißt Aware ${ }^{6}$ ).

1) Ebenda S. 325, 338.

2) Pauli diaconi Hist. Langob. V c. 17.

8) Vgl. oben n. 3.

4) Daß man trotz des turanischen Einschlages in cier Sprache die Resianer nicht mit Fligier einfach für slawisierte Awaren halten dürfe, hat Tappeiner auf Grund anthropologischer Untersuchungen festgestellt (Zur Ethnographie und Anthropologie der Resianer, Sitzungsberichte der anthropologischen Gesellschaft in Wien 1895 S. 67). Das Fehlen turkotatarischer Rassenmerkmale und daneben doch wieder das Vorhandensein turkotatarischer Spracheigenheiten läßt sich aber dann nur durch die obige Annahme eines längeren Zusammenlebens von kleinen awarischen Horden mit großen slowenischen Massen erklären (gegen Niederle a. a. O. II. S. 348 n. 1).

5) Monumenta historica ducatus Carinthiae (Mon. hist. duc. Car.) Bd. II. und IV 2 Register.

o) Jaksch, Über Ortsnamen und Ortsnamenforschung mit besonderer Rücksicht auf Kürnten S. 34. 
Allein die Awaren begnügten sich nicht damit, die unterjochten Völker durch Besatzungen im Zaume zu halten, sondern rissen siè überdies von ihrem Heimatboden los und verpflanzten sie in die Fremde ${ }^{1}$ ), da sie hofften, dadurch in ihnen desto sicherer jeden Geist des Widerstandes zu ertöten. Einen Beleg dafür aus ehemals slowenischem Gebiete liefert der Name Dudleipa.

Nachrichten aus dem 9. Jahrhundert erwähnen in Mittelsteiermark einen Ort Dudleipin ${ }^{2}$ ) und eine Grafschaft Dudleipa ${ }^{3}$ ). Wie ein Vergleich mit rimljanin, blgarin, den slawischen Bezeichnungen für Römer, Bulgare, dartut, ,ist - in “ die Bildungssilbe für die Einzahl von Volksnamen, sodaß Dudleipin eigentlich der Dudleipe heißt und nur irrtümlich in jenen Nachrichten als Ortsname erscheint. Der wirkliche Ortname ist mit Hilfe der weiblichen Endung $n-a^{*}$ gebildet. und lautet Dudleipa. Er bezeichnete zuerst bloß die Zufluchtsstätte des Stammes, den "grad", den sich die Dudleben nach gemeinslawischer Sitte im Herzen ihres Landes für die Zeiten der Not geschaffen hatten. Erst als dann in karolingischer Zeit das Siedlungsgebiet der Dudleben als Grafschaft eingerichtet ward, ging der Name des Hauptortes auf: den ganzen Bezirk über.

Merkwürdigerweise wohnten aber Dudleben nicht nur in Mittelsteier, sondern, wie Dulieb bei Spital an der Drau ${ }^{4}$ ) bezeugt, auch im westlichen Kärnten. Da es ausgeschlossen ist, daß verhältnismäßig so nahe nebeneinander $\mathrm{zwei}$ verschiedene slowenische Stämme desselben Namens gesessen haben könnten, so fragt man sich verwundert, woher die beiden grundverschiedenen Lautformen rïhren: hier das südslawische weiche $\mathrm{l}$, dort das westslawische dl in Stallvertretung des harten l. Um darüber urteilen zu können, bedarf es eines Abstechers in die Entwicklungsgeschichte der slowenischen Sprache.

1) Pauli diaconi Hist. Langob. IV c. 37 : Den im Jahre 610 gefangenen Friaulern versprachen die Avaren „quod eos, unde digressi fuerant, Pannoniae in finibus conlocarent. - Menandri Protectoris Fragmenta c 6 (Historici graeci minores, ed. Dindorf II p. 6): Nachdem die Awaren den Führer der Anten erschlagen

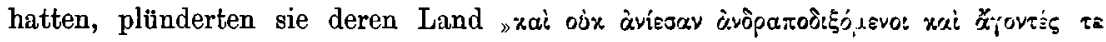
xai pépovtes. - Vgl. auch die Verpflanzungen, die die Bulgaren mit den Slawen vornahmen: Schafarik, Slawische Altertümer II. S. 164. - Niederle a. a. O. II S. 407. - Jireček, Geschichte der Bulgaren S. $129 \mathrm{f}$.

2) Conv. Bag. et Carant. c. 11 (MG. SS. XI, S. 12). - Mählbacher, Regesten der Karolinger n. $1444=$ Salzburger Urkundenbuch II n. 21.

9) Zahn, Urkundenbuch f. Steiermark I $14=$ Hauthaler, Salzburger Urkundenbuch II n. $35^{\mathrm{b}}=$ Mühlbacher, Regesten der Karolinger n. 1858.

4) Jaksch, Mon. hist. duc. Car. III S. 132 n. 331 (c. 1(60-1070). 
Șchon öfter haben slawische Forscher aufmerksam gemacht, daB im Slowenischen scheinbar cechische Formen nachweisbar sind und zwar die Lautgruppe dl statt 1, die Vorsilbe vy- für iz (-aus) ${ }^{1}$ ) und die geographischen Eigennamen Kum, Kulm und Kulmitz, die anscheinend ein čechisches chlum voraussetzen, da dem slowenischen holm nur Kolm und Kolmitz entspräche ${ }^{2}$ ).

Beispiele für solche Formen gibt es in Hülle und Fülle. So finden sich in Ober- und Mittelsteiermark mehrere Edla und Edlach, die ohne Zweifel aus dem èechischen oder, vorsichtiger gesagt, westslawischen jedla - die Tanne (slow. jela) abgeleitet sind. Bei Weiz liegt ferner ein Dorf Elz, dessen alte Namensform Edlitz deutlich beweist, daß Elz aus dem Verkleinerungsworte von jedla, jedlica - die kleine Tanne (slow. jelica) entstanden ist ${ }^{3}$ ) und selbst tief drunten bei Udine in Friaul verrät ein Ortsname Adegliacco durch die urkundliche Überlieferung Edilach-Edelac, daß auch er auf jedla zurückgeht ${ }^{4}$ ). Dasselbe dl liegt ferner im Worte močidlo vor, das uns aus Matschiedel im Gailtal und Muntschiedel bei Frohnleiten entgegenklingt ${ }^{5}$ ). Andere Namen bergen wieder ein cechisch anmutendes sedlo, sedlice in sich anstatt des jetzt im Slowenischen gebräuchlichen selo (die Ansiedlung), selice (die kleine Ansiedlung). Dahin gehören in Tirol Zedlach bei Windisch-Matrei ${ }^{6}$ ), in Obersteiermark an der Enns Selztal, das noch 1289 urkundlich als Cedlize erscheint ${ }^{7}$ ) und dann ein Dorf im Görzischen, das zwar nach amtlicher Schreibweise Staro selo heißt, im Volksmunde aber noch bis in die achtziger Jahre des vorigen Jahrhunderts Staro sedlo genannt wurde ${ }^{8}$ ). Besonders auffällig häufen sich jedocb Namen dieser Art in Kärnten ${ }^{9}$ ). Dort gibt es ein :

Zedl oder Zedlach in der Pfarre Altenmarkt, Bezirksgericht Gurk; Zedl bei Silbereg, Bezirksgericht Althofen;

1) Miklosich, Die slawischen Ortsnamen aus Appellativen. Denkschriften der k. Akademie in Wien, Bd. 21, S. $105 \mathrm{f}$. Oblak, Kleine grammatische Beiträge (Archiv f. slaw. Philologie, 19. Bd., S. 321, 326). - Herr Univ.-Prof. Dr. R. Nachtigall hatte die große Liebenswürdigkeit, den Verfasser bei der Korrektur mit wertvollen philologischen Ratschlägen zu unterstützen. Dafür gebührt ihm der wärmste Dank.

2) Niederle a. a. O. II S. 356; ders., Jak daleko sedèli Čechové na jih ? Ċasopis česky historicky 1909 S. 74.

s) Zahn, Ortsnamenbuch der Steiermark S. 161, 167.

4) Jaksch, Mon. hist. duc. I S. 56 n. 16 (1043), 102 n. 61 c (1131).

5) Oblak a. a. O. S. 321.

8) Kaemmel, Anfänge deutschen Lebens in Österreich S. 146.

7) Zahn, Ortsnamenbuch S. 460.

8) Scheinigg, Krajerno ime Selo na Kranjskem, Kres Bd. 2, S. 640.

9) Zusammengestellt ebenda S. 639-41. 
Zedl in der Gemeinde Radenthein, Bezirksgericht Millstatt;

Zedl in der Gemeinde Steinfeld, Bezirksgericht Greifenburg;

Zedl bei Pfannhof, Bezirksgericht St. Veit;

Zedl bei Pisweg, Bezirksgericht St. Veit;

Zedlingerhof bei Maria-Saal, Bezirksgericht St. Veit;

Zedlitzdorf in der Gemeinde Reichenau, Bezirksgericht Feldkirchen;

Zedlitzberg in der Gemeinde Himmelberg, Bezirksgericht Feldkirchen.

$\mathrm{Da}$ im Slowenischen für selo auch die Form salo möglich ist, so darf man in diese Liste außerdem noch drei andere Dörfer aufnehmen, pämlich:

Sattendorf (Na Sadlè) am Ossiacher-See;

Großsatl (Sadlò) in der Pfarre Maria-Gail bei Villach;

Kleinsatl (Malo sadlò) in der Pfarre Maria-Gail bei Villach.

Aber nicht nur in längst erstarrten Ortsnamen lebt die Lautgruppe dl fort, sondern das slowenische Volk spricht sie noch heute sowohl in der westlichen Untersteiermark als insbesonders im Gailtal. Dort sagt man modliti (beten), vedlo listje (welkes Laub) ${ }^{1}$ ), hier gebraucht man dl in plačidlo (der Lohn), motovidlo (die Haspel) und noch in vielen anderen Hauptwörtern. In der tätigen Form des Mittelwortes der Vergangenheit aber ist es überhaupt jedem Slowenen in Kärnten, Untersteiermark und Oberkrain greläufig, sodaß man zum Beispiel nie hören wird „krala je“ (sie hat gestohlen), sondern nur "kradla je" 2 ).

Auch die westslawische Vorsilbe vy ist bei den Slowenen noch zu verfolgen. Sie kommt in der Resia vor, wo man sagt "sunce vylaza" (die Sonne geht auf) ${ }^{3}$ ) und auch die Drauslowenen vom Bachern durchs Jaun- und Rosental bis an den Ursprung der Gail verwenden das vy, indem sie den Frühling vilaz nennen ${ }^{4}$ ). Zusammen mit den über Steiermark und Kärnten verstreuten Kum, Kulm und Kulmitz ${ }^{5}$ ) lehrt diese Übersicht, daß im ganzen Nordwesten des slowenischen Siedlungsgebietes einst ans Čechische anklingende Mundarten herrschten.

Niederle möchte diese westslawischen Formen zum Teil auf wirklich čechische Kolonien in den slowenischen Alpenländern zurückführen. Indem er auf Grund der geographischen Verteilung einiger von ihm mitgeteilter Ableitungen ans chlum und jedla urteilt, daß

1) So in Hl. Kreuz bei Marburg auf dem Poßruck.

2) Sämtliche Beispiele aus Oblak, a. a. O. S. $321 \mathrm{ft}$.

3) Baudouin-de-Courtenay, a. a. O. S. 276.

4) Oblak, a. a. O. S. 327.

5) Niederle, Jak daleko sedèli Cechové na jih? Čas. Česky hist. 1909 S. 74. - Zahn, Ortsnamenbuch. 
Ortsnamen dieser Stämme in Kärnten und Krain gefehlt hätten, stellt er es als sehr wahrscheinlich hin, „daß ein Keil čechischer Siedlungen von der Donau zwischen Enns und Leitha über Wiener-Neustadt bis an die Mürz und Mur, ja sogar bis an die Drau gereicht habe" 1). Doch es ist leicht einzusehen, daß diese Annahme auf irrigen Voraussetzungen beruht. Denn 1. wissen wir schon aus unseren früheren Ausführungen, daß sich die mit chlum und jedla gebildeten Namen gar nicht auf Steiermark nördlich der Drau beschränkten - man findet sie vielmehr auch in Kärnten, sogar in Friaul ${ }^{2}$ ) - und 2. müßte, wer Bezeichnungen wie Edlach, Kulm und deren Verwandte auf eechische Sprachinseln bezieht, folgerichtig auch alle anderen westslawischen Formen mit alten Cechensiedlungen in Verbindung bringen. Fr könnte diesem Schlusse nur dann ausweichen, wenn es ihm gelänge darzutun, daß das dl wohl in Edlach aus cechischem Munde stamme, nicht aber zum Beispiel auch in einem Zedlach. Da jedoch ein solcher Beweis unmöglich und undenkbar ist, so dürfte man nicht mehr bloß von čechischen Sprachinseln reden, sondern könnte nicht umhin, über Niederle hinausgehend, aus der weiten und gleichmäßigen Verbreitung nordslawischer Formen in den Alpenländern auf ein zusammenhängendes čechisches Sprachgebiet zu schließen. D. h. die Vorfahren der heutigen Slowenen in Kärnten, Steiermark und Oberkrain wären dann echte Cechen gewesen, die erst durch das Vordringen deutscher Siedler längs der Donau die Verbindung mit ihren Brüdern in Böhmen verloren hätten und dem Südslawentum überantwortet worden wären. Allein dem widerspricht wiederum sehr bestimmt der innere Bau des Nordwestslowenischen, der vom Čechischen stark abweicht. Die lautliche Verwandtschaft beider Sprachen ist daher nicht aus der eechischen Herkunft der Alpenslawen zu erklären, sondern daraus, daß bəi der Auswanderung der Slowenen aus ibrer hinterkarpatischen Heimat ihr westlicher Flügel in inniger Fühlung mit den Čechen blieb und so das alpenländische Slowenisch naturgemäß das Bindeglied zwischen dem Cechischen und Südslawischen wurde ${ }^{3}$ ).

Wie man nun aus Gegenden weiß, deren Bewohner das einst nachweislich dort heimische dl längst nicht mehr kennen, gingen und gehen die westslawischen Formen in den Alpenländern ständig zu Gunsten

1) Niederle, Slovanské staražitnosti II S. 354, 35̌6. - Ders., Jak daleko sedèli Cechové na jih? S. 75 .

2) Vgl. oben S. 235.

s) Vgl. Oblak, a. a. O. S. 328. 
der südslawischen zurück ${ }^{1}$ ). Diese Tatsache verlangt besondere Beachtung. Denn durch sie gewinnen wir einen neuen Gesichtspunkt zur Beurteilung der Dudlebenfrage, zwingt sie uns doch zu überlegen, ob nicht auch das kärntnerische Dulieb einst Dudleipa geheißen habe, d. h. nur die südslawische Umbildung einer früher gebräuchlichen westslawischen Urform sei. Da Dulieb ohnehin erst zwischen 1060 und 1070 genannt wird, das steirische Dudleipin dagegen zum letzenmale um 980 in einer Urkunde Ottos II. erscheint ${ }^{2}$ ), so wäre auch ein zeitlicher Zwischenraum von etwa hundert Jahren vorhanden, innerhalb deren man sich die Umwandlung ins Südslawische vollzogen denken könnte. Trotzdem ist das Ganze nur eine luftige Annahme. Das älteste und einzige Beispiel aus dem ganzem Mittelalter, das man bisher für die Vereinfachung von dl zu 1 anzuführen wußte, war die aus dem Jahre 1289 überlieferte Form Jelonig für Jedlonig, einen Ort nordwestlich von Marburg ${ }^{3}$ ). DaB sie gut zweihundert Jahre jünger ist als unser Dulieb, schon das mahnt zur Vorsicht gegen jene Vermutung. Nichts desto weniger wollen wir den Übergang Dudleipa-Dulieb zunächst noch als möglich annehmen.

Nun gibt es aber im Gebiete des Nordwestslowenischen echt südslawische Formen schon aus einer Zeit, da an einen solchen Übergang noch nicht zu denken ist. In Oberkrain wird ein Zelsach schon 973 erwähnt ${ }^{4}$ ) und für Kärnten ist derselbe Name gar noch viel früher bezeugt. Denn das Zulszach, das eine Urkunde von 898 bringt ${ }^{5}$ ), verrät. durch seine später belegten Formen Zelsach ${ }^{6}$ ) sehr deutlich, das es sich trotz des u gleich dem krainischen Zelsach aus dem südslawischen selice entwickelt hat. Ein westslawisches sedlice wäre in die Urkunde höchstens als Zedelsach oder Sediltzach 7) übernommen worden. Ist aber das kärtnerische Zulszah, das krainische Zelsach v on Haus a us südlawisch, so könnte es vielleicht Dulieb doch ebenfalls sein? Der einen Möglichkeit, Dulieb für eine jüngere Bildung aus westslawischer Wurzel zu

1) Ebenda S. 321 .

2) Mon. Germ. DD. II S. 319 n. 275.

3) Oblak, a. a. O. S. 321 .

4) Mon. Germ. DD. II S. 56 n. 47. - Zahn, Cod. dipl. Austro-Fris. I S. 36 n. 37 (Font. rcr. austr. dipl. Bd. 31). - Schumi, Urkunden und Regest. f. Krilin I S. 10 n. 8 .

5) Jaksch, Mon. hist. duc. Car. I S. 42 n. 4.

8) Ebenda I S. 94 n. 58 (1130), 170 n. 214 (1160), 264 n. 354 (1192), 272 n. 369 (1197), 275 n. 373 (1199) u. s. w.

7) Gerade für Zeltschach ist auch diese westslawische Form urkundlich belegt: Mon. hist. duc. Car. I S. 65 n. 23 (1060-1088), 85 n. 40 (1106), 133 n. 138 (1145), 157 n. 193 I (c. 1156), 44 n. 5 (1172-1176). 
halten, tritt so die zweite an die Seite, daß die Form Dulieb eine ursprüngliche, nicht erst nachträglich südslawisierte sei. Welche Anschauung richtig ist, erkennt man, wenn man die sprachlichen Verhältnisse in der Nachbarschaft von Dulieb untersucht.

Man wird da gewahr, daß dieser Ort am Rande eines weiten kroatischen Siedlungsgebietes lag. Nach Urkunden des 10. Jahrhunderts gab es nänlich in Kärnten einen eigenen Kroatengau 1). Zwar erfährt man nichts über seine Grenzen und auch die Dörfer, die in ihm genannt werden, erscheinen auf einen so kleinen Raum westlich von St. Veit an den Glan zusammengedrängt, daß man sich daraus vom Umfange des Gaues keine Vorstellung machen kann. Trotzdem ist es gewiß, daß sich die Kroaten sehr weit verbreitet haben müssen, sonst träfe man nicht ein Kraut, einst (hroat 2), bei Millstatt, je ein Krabathen bei Eberstein, Feldkirchen und Klagenfurt und ein Kraubath sogar jenseits des Neumarktes Sattels im oberen Murtal.

Man sollte erwarten, daß ein solcher Zuschuß rein südslawischen Volktums die westslawischen Laute in diesen Strichen besonders früh habe verstummen lassen. In Wirklichkeit ist jedoch davon nichts zu spüren. Namen wie Zedl, Zedlitzberg, Zedlitzdorf, Kulm lebten hier ruhig fort, noch dazu, was verblüffend ist, in der Nähe kroatischer Siedlungen. Zedlitzberg liegt neben einem Krabathen, Kulm bei Eberstein neben einen zweiten Krabathen und Kulm bei Eberndorf nicht weit von Sielach, dem alten Zelach ${ }^{3}$ ), dem man die südslawische Lautgebung sofort ankennt; denn wäre die Grundform des Namens westslawisch gewesen, so hätte der Ort in den Urkunden Zedlach geheißen.

Unsre oben noch als möglich hingestellte Annahme, Dulieb sei aus einem alten Dudleipa hervorgegangen, ist durch diese Zusammenstellung wohl endgiltig abgetan. Denn wenn das Südslawische selbst im Herzen des kroatischen Siedlungsgebietes zu schwach war, um westslawische Formen rasch aufzusaugen, dann konnte es an der Grenze des Kroatenlandes - und Dulieb lag ja im äußersten Westen - dazu erst recht nicht fähig sein. Wie wenig man von sprachlichen Eroberungen des Kroatischen in Kärnten zu halten hat, dafür nur noch ein schlagender Beweis. Bei Friesach liegt das Dorf Zeltschach. In der schon erwähnten Urkunde von 898 heißt es Zulszah, d. i. das südslawische Zelsach. In der zweiten Hälfte des 11. Jahrhunderts

\footnotetext{
1) Ebenda III S. 45 n. 11 á (954), S. 50 n. 125 (961), S. 62 ฉ. 149 (979).

2) Ebenda III S. 140 n. 352 (c. 1065 -c. 1075), S. 143 n. 360 (c. $1065-$ c. 1075).

3) Ebenda III S. 216 n. 535 (1106).
} 
und dem folgenden zwölften jedoch erscheint derselbe Name öfter in der westslawischen Form Zedelzah, Sedelsah!1)

Nicht westslawische Formen haben sich also hier frühzeitig in südslawische verwandelt, sondern umgekehrt waren diese sogar noch im 12. Jahrhundert in Gefahr, von jeuen verdrängt zu werden. Der Grund dafür konnte nur der sein, daß sich im Klagenfurter-Becken die Massen des durch westslawische Eigenheiten entstellten Nordwestslowenischen bedienten und nur eine dünne Volksschicht in südslawischen Lauten redete.

Der Ertrag unsrer sprachgeschichtlichen Darlegungen besteht somit darin, da $B$ man Dulieb nicht als Umbildung von Dudleipa, sondern als Urform anzuerkennen hat. Damit ist aber das Rätsel DuliebDudleipa auch schon gelöst. Denn man braucht sich nur zu erinnern, daß es ja noch an zwei Stellen in der weiten slawischen Welt Stämme dieses Namens gab: in Südböhnen die Dudlebi und am galizischen Bug die Duljeben ${ }^{2}$ ). Stellt man sich dann die geographische Lage der vier Duljebengebiete vor und beachtet man namentlich die paarweise l̈bereinstimmung der Namensformen im Osten und Westen: Duljeby-Dulieb, im Norden und Süden: Dudlebè-Dudleipin, so wird es klar, daß alle Duljeben aus den Niederungen des Bug stammen. Nur wurden ihr Name in Böhmen und Steiermark westslawisiert, während er sich in Kärnten rein erhielt, weil dort der kroatische Einschlag die sprachliche Aufsaugung hemmte.

Man kennt keinen Stamm der Völkerwanderungszeit, der sich freiwillig über so riesige Flächen und in so klejnen Verbänden wie die Duljeben zerstreut hätte; im Gegenteil, aus der Entstehungsgeschichte der germanischen Stämme weiß man, daß in wilden Zeiten der Selbsterhaltungstrieb gerade Zusanmenfassung aller Kräfte gebietet. Zersplitterung, darf man daher sagen, setzt Gewalt voraus; die aber kann, wie die Dinge einmal liegen, nur von den Awaren ausgegangen sein. Sie müssen den Daljebenstamm zerschlagen und seine Trümmer hierhin und dorthin verpflanzt haben.

Diese Schlüsse werden nun auch durch verschiedene Schriftsteller gestützt, deren Worte sich gegenseitig aufs Beste ergänzen. Wir beginnen mit Mas'udi, einem arabischen Gewährsmanne des 10. Jahrhunderts. Der schreibt: ${ }^{3}$ )

"Inter den slawischen Nationen gibt es eine, bei der vor alters im Anfange der Zeit die Herrschaft stand. Ihr König wurde Mağak

1) Vgl. oben S. 238 n. 7.

2) Marquart, Osteuropäische und ostasiatische Streifzüge S. 125.

3) Marquart, a. a. O., S. $101 \mathrm{ff}$. 
genannt. Diese Nation heißt Walinjana und ihr pflegten vor alters die übrigen Slawenstämme zu gehorchen".

Im Anschluß an diese Stelle zählt nun Mas'udi die slawischen Stämme auf, darunter die Čechen, Mährer, Kroaten und die Slawen von Braničevo; dann fährt er fort:

"Die Slawen bestehen aus vielen Völkern und ausgebreiteten Abarten, deren Beschreibung und Einteilung vorliegendes Buch nicht zu Ende führen will. Die Geschichte von dem Könige, dem ihre Könige sich in alter Zeit fügten, d. i. von Mağak, dem Könige der Walinjana, haben wir schon vorausgeschickt. Dieses Volk, das zu den Slawenstämmen reinsten Blutes zählt, war unter ihnen hoch geehrt und konnte sich auf alte Verdienste unter ihnen berufen. Hierauf trat Uneinigkeit ein, ihre Organisation hörte auf und ihre Nationen schlossen sich (einzeln) zusammen; jede Nation machte einen König über sich, nach der Anzahl ihrer Könige, die wir erwähnt haben, aus Ursachen, deren Erzählung zu lang wäre".

Marquart hat, gestïtzt auf Nestors Chronik, bemerkt, daß Wolynjane der jüngere Name für die russischen Duljeben war, die am Bug saßen und zu dem großen Volke der Anten gehörten 1). Da es infolgedessen schon geographisch undenkbar ist, daß sie, wie man nach Mas'idi vermuten könnte, auch über die Čechen und die Slawen des Westbalkans geherrscht hätten, so bleibt als möglicher Kern von Mas'udis Bericht nur die Annahme übrig, die Duljeben hätten sich vor alters ein Großreich unter den Anten geschaffen, das aber wieder zugrundegegangen sei.

Damit stimmt danu recht gut die bekannte Stelle bei Nestor überein, wo es heißt:

„Die Awaren unterwarfen sich im Kampfe gegen die Slawen die Duljeben und taten ihren Weibern Gewalt an. Wenn ein Aware irgend wohin zu fahren hatte, so ließ er weder Pferd noch Stier anspannen, sondern ließ drei, vier oder fünf Weiber an sein Fuhrwerk schirren und sich von ihnen fahren. Also quälten sie die Duljeben “ 2).

Arbeitet man Nestors und Mas'udis Nachrichten ineinander, so glaubt man auf einmal, nicht nur zu verstehen, wi e das Duljebenreich unterging, sondern auch wann und warum. Denn dann urteilt man folgendermaßen:

So lange ein großes Antenreich bestand, war den Awaren der Weg über die Karpathen nach Ungarn verlegt. Wollten sie dahin, so

1) Ebenda S. XXXVI und $146 \mathrm{f}$.

2) Miklosich, Chronica Nestoris S. $5 \mathrm{f}$. 
mußten sie um jeden Preis trachten, dieses Hindernis zu zerstören. Als ihnen das - man setzt voraus, nach erbitterten Kämpfen endlich gelungen war, ließen sie ihre Wut gerade an denen aus, die die Stämme der Anten zu gemeinsamem Widerstande zusammengefaßt hatten und das waren die Duljeben. Der Beginn der awarischen Herrschaft über dieses Volk fiele dann zwischen 558 und 563 , - nicht früher, da die Awaren erst 558 Nachbarn der Anten geworden 1), nicht später, da der Raubzug der Awaren nach Ungarn von 563 den Fall des Duljebenreiches zur Voraussetzung hat ${ }^{2}$ ). Ohne ihn wären die Karpathenpässe nach wie vor gesperrt $\mathrm{g}$ zblieben.

Es ist mißlich, daß sich diese weitgehenden und bestechenden Schlüsse vorerst uur auf zwei, noch dazu undatierte Nachrichten gründen, zwischen denen die Phantasie allein die Brücke geschlagen hat. Wir kämen daher nje über Wahrscheinlichkeitsrechnungen hinaus, wenn wir nicht eine byzantinische Quelle zum Vergleiche heranziehen könnten. Aus Menander erkennt man nämlich, daß um 558, als die Awaren noch in Südrußland hausten, die Anten zum Unterschied von den übrigen Slawen eine gewisse politische Einheit unter Mezamer, dem vornehmsten ihrer Häuptlinge bildeten ${ }^{3}$ ). Der Eindruck dieser wenn auch gewiß lockeren Reichsschöpfung mitten im staatenlosen Völkergewimmel des Ostens war so nachhaltig, daß Mezamers Name in der Form Bezmer sogar in die bulgarische Fürstenliste überging ${ }^{4}$ ). In der Tat war die Macht seines Antenbundes groß genug, um längere Zeit die awarische Flut zu stauen. Erst als die Awaren Mezamer, der als Gesaudter zu ihnen gekommen war, ohne Scheu vor dem Völkerrecht ermordet hatten, überwanden sie sein führerloses Volk und "seither, sagt Menander, hörten sie nicht auf, die Anten zu knechten und nach allen Richtungen zu verschleppen“5).

$\mathrm{Zu}$ unsrer Genugtuung finden wir hier Punkt für Punkt die oben geäußerten Vermutungen durch Menander bestätigt. Es gab also wirkiich so etwas wie einen Antenstaat, den die Awaren nach 558 vernichteten, nachdem sie den Häuptling des führenden Stammes aus dem Wege geräumt hatten. Ja, selbst die Herrschernamen stimmen bei Mas'udi und Menander überein. Denn Magak ist nichts anderes als der Kurzname für Mezamer, ähnlich gebildet wie Misaco aus Mistislav.

1) Menandri Protectoris Fragmenta cap. 2-3 (Dindorf, Historici graeci minores II.).

2) Marquart a. a. O. S. 147.

3) Menandri Protectoris Fragmenta cap. 6.

4) Marquart, Chronologie der alttürkischen Inschriften S. 78.

5) Menandri Protectoris Fragmenta cap. 6. - Vgl. oben S. 234 n. 1. 
Wir schließen daher mit der Einsicht, das Mezamer derselbe war wie Magak, nämlich der Fürst der Duljeben ${ }^{1}$ ).

Nun aber exinnere man sich: aus Mas'udi-Nestor-Menander ist bekannt, daß nach Mezamers Tode die Angehörigen des Duljebenstaates von den Awaren verschleppt wurden, aus Ortsnamen aber wissen wir, daß es später in Mittelsteiermark und Kärnten Duljeben gab. Beide Tatsachen verlangen gebieterisch nach Verknüpfung, die aber kann nur ergeben, daß die Awaren um 560 Duljeben aus ihrer Heimat mit sich fortschleppten und ihnen nach dem Abzug der Langobarden aus Pannonien in den Alpenländern Sitze anwiesen. Hier inmitten fremder Slawen schieneu sie ihnen nicht mehr gefährlich.

Unsre Untersuchungen über die Ortsnamen Dudleipa-Dulieb geben also, gleichviel ob sprachgeschichtlich, ob quellenmäßig geführt, die Gewißheit, daß auch auf slowenischem Boden die Awaren durch Verpflanzungen dafür sorgten, ein Völkerchaos zu schaffen, damit die unterjochten Slawenmassen, jedes Gefühls der Zusammengehörigkeit bar, unfähig wären zu geneinsamer Erhebung und in dumpfem Gleichmut auch die ärgste Knechtschaft ertrügen.

Allein die Natur des slowenischen Siedlungsgebietes läßt uns vermuten, daß zum Glück die awarische Herrschaft trotz aller Gewaltmittel nicht überall gleichfest begründet gewesen sei, daß sie namentlich in Kärnten schwächer gewurzelt habe als irgendwo anders. Denn wir dürfen mit sehr viel Wahrscheinlichkeit annehmen, daß die Awaren hier nur selten in größeren Scharen erschienen seien. Was hätte sie auch reizen sollen, allzu oft längs der Drau auszuschwärmen und in Kärnten den Herrn zu zeigen? Wirtschaftlich hatte ja dieses Land für sie sehr wenig Wert. Denn im Sommer waren ihre Herden ohnehin in den Steppen Ungarns versorgt, im Winter aber werden sich die Awaren gehütet haben, Kärnten aufzusuchen, weil bei der eisigen Kälte des schneereichen Klagenfurtır Beckens ihr Vieh Monate lang ohne Scharrfutter geblieben wäre und die plumpe Wirtschaftsform der slawischen Knechte auch nicht darnach angetan war, im Sommer so viel Heu zu beschaffen, daß es im Winter außer für die awarischen Besatznngen auch noch für große Horden mit zahlreichem Vieh gereicht hätte. Es bliebe mithin nur die Möglichkeit offen, daß Kärnten wenigstens als Durchzugsland nach dem Westen den Awaren wertvoll gewesen sei. Allein auch dieser Gedanke ist aus verschiedenen Gründen abzulehnen. Vor allem war der riesige Drauwald an der steirisch-kärtnerischen

1) Marquart, Osteuropäische Streifzüge S. 147. 
Grenze 1) und das enge Durchbruchstal zwischen Bachern und Poßruck dem Fortkommen großer Reitermassen nicht günstig. Dann aber mußte ein Vorstoß längs der Drau den Awaren auch zwecklos erscheinen, weil die Draustraße eine Sackgasse war, die nur in die Alpenwildnis Tirols hineintührte und daher keine Aussicht auf Beute bot. Ungleich wichtiger war ohne Zweifel für die Awaren die Linie nach dem Südwesten. Hier konnten sie nicht nur bequem der Römerstraße folgen, die vom Plattensee über Pettau, Cilli und von dort über Laibach und den Birnbaumer Walde ins breite Wippachtal ging, sondern hier waren sie anch sicher, unterwegs, im klimatisch günstigeren LaibacherBecken, Winterquartiere und am Ziel, in Italien, ein reiches altes Kulturland zu finden.

Dem Naturzwang, den diese Richtung auf die Völker Pannoniens übte, waren vor den Awaren Hunnen, Goten und Langobarden erlegen ${ }^{2}$ ), derselbe Zwang trieb später auch die Magyaren so oft durch Krain an den Po, daß bis ins 11. Jahrhundert der Ausläufer der pannonischen Straße in Friaul geradezu „Ungarnweg“ hieß ${ }^{3}$ ), ja, daß sich noch heute ein Ort bei Görz bezeichnenderweise "Vogrsko" (Ungarndorf) ${ }^{4}$ ) nennt. Die nämliche Politik, in deren Dienst die Awaren Jahre lang mit den Byzantinern um Sirmium rangeu ${ }^{5}$ ), mu(Bte ihnen raten, auch Untersteiermark-Krain in straffer Abhängigkeit zu halten. Denu der Besitz dieser Ausfallstore im Osten und Westen machte den Chagan der Awaren zum Herrn der reichsten Länder Europas, stand es doch dann in seinem freien Belieben, bald Ostrom, bald Italien zu plündern. Oder sollten die Awaren für solche Vorteile keinen Sinn gehabt haben? Wenn doch, dann trugen die Kosten einer solchen Politik im Westen die Slawen von Untersteier und Krain, die nur zu oft awarische Horden bei sich zu Gaste gesehen haben werden und dann waren die Slowenen an der Sawe auch geradezu vorherbestimmt, besonders lange und nachdrücklich die volle Wucht des-awarischen Druckes auf sich zu fühlen.

1) Die Bedeutung des Drauwaldes als Grenzscheide erhellt auch aus der eben durch ihn gerechtfertigten Bezeichnung »marchia transsylvana für die Gegend von Gams ob Marburg: Krones, Verfassung und Verwaltung der Mark und des Herzogtums Steier, Forschungen zur Verfaseungs- und Verwaltungsgeschichte der Steiermark Bd. I S. 25.

2) Schmidt, Allgemeine Geschichte der germanischen Völker S. 82, 94.

s) Mon. Germ. DD. I S. 466 n. 341 (967). Bresslau, Jahrbủcher des deutschen Reiches unter Konrad II. Bd. I., S. 485 n. 3 (1028).

4) Kos a. a. O., Bd. II S. LI.

5) Menandri Protectoris Fragmenta c. 63-64. 
Wir leiten dies aus rein geographischen Erwägungen ab. Nach den folgenden Zeilen möge man entscheiden, ob diese geographischen Vernutungen wenigstens dureh die Ereignisse nach dem Sturz der awarischen Macht gerechfertigt werden.

\section{Die Zeit Samos.}

Schlag auf Schlag ging im ersten Drittel des 7. Jahrhunderts das Unglück über die Awaren nieder. Kroaten und Serben vernichteten deren Macht im westlichen Teil der Balkanhalbinsel ${ }^{1}$ ), siegreich wies Konstantinopel 626 die Stürme des Chagans ein für allemal $\mathrm{ab}^{2}$ ) und wie sich im Westen ein freier Slawenstaat unter dem Franken Samo erhob $^{3}$ ), so ergriff im Osten Kubrat, der Chan der Unugundur-Bulgaren Bessarabiens, die Gelegenheit, um das awarische Joch zu zertrümmern ${ }^{4}$ ).

Während der inneren Wirren, die diesem Zusammenbruch folgten, flohen 9000 pannonische Bulgaren vor den Awaren nach Bayern. Als man aber dort auf Befehl des Frankenkönigs Dagobert meuchlings über sie herfiel, retteten sich 700 unter der Führung Alzioks in die "Wendenmark" des Fürsten Walluk ${ }^{5}$ ). Von hier wanderten sie dann zu den Langobarden und gründeten sich in den Abruzzen eine neue Heimat. ${ }^{6}$ )

Die Lage und politische Stellung dieses Slawenstaates ist klar. Denn daß die Bulgaren vor Bayern und Awaren bei Walluk Schutz fanden, beweist die Unabhängigkeit seines Reiches und daß die "Windische Mark" am Wege von Bayern nach Oberitalien lag, gestattet mit Sicherheit den Schluß, daß das obere Drautal zu ihr gehörte. Hie $r$ hatten sich also die Slowenen beim jähen Sturz der awarischen Macht ihrer Zwingherrn entledigt.

Allein die Geschichte von der Flucht der Bulgaren läßt nur den Mindestumfang des befreiten Slowenenlandes erraten, verhehlt jedoch, ob sich in diesem Staate nicht etwa gar alle Slowenen zum Kampfe gegen die Awaren zusammengeschlossen haben. Die Antwort auf diese Frage holte man sich lange Zeit aus Fredegar und der Conversio, die beide teils mittelbar, teils geradeaus sagen, daß König Samo auch über die Karantaner geherrscht habe. Indem man diese Angabe mit der

1) Dümmler, Über die älteste Geschichte der Slawen in Dalmatien (Sitz.-Ber. d. k. Ak. d. Wiss. in Wien Bd. 20, s. 353).

2) Jireček, Geschichte der Bulgaren S. 91.

3) Fredegarii Chronicon lib. IV cap. 48.

4) Marquart a. a. O. 126, 194.

5) Fredegarii Chronicon IV cap. 72.

8) Pauli Diaconi Historia Langob. V cap. 29. 
Nachricht über Walluk verband, folgerte man, die "Windische Mark" sei Karantanien gewesen und Walluk daher ein Fürst der Karantaner, der gegen die äußeren Feinde Anlehnung an Samo gesucht habe ${ }^{1}$ ).

Gegen diese Auffassung wurden nun quellenkritische Bedenken lant, die schließlich so weit gingen, daß man Samos Karantaner-Herrschaft ins Reich der Fabel verwies. Der Awarenbezwinger, den man früher allgemein als Oberherrn eines großen Slawenbundes vom Erzgebirge bis in die südlichen Alpen angesehen hatte, mußte es sich auf einmal gefallen lassen, daß ihn Goll in den bescheidenen Rang eines Cechenbefreiers erniedrigte 2). Damit nicht genug, bestritt man schließlich auch dies. Denn da man über die Sitze der von Samo beherrsehten Slawen nichts unmittelbar aus den Quellen erfuhr, so machte man sich daran, sie durch Kettenschlüsse festzustellen. Man überlegte: 631 unternahm Dagobert mit drei Heeren, darunter einem fränkischen und einem alemannischen, einen Angriff auf Samo. Nachdem dieser Zug zum Teil mißglückt war, brach Samo wiederholt in Thüringen verheerend ein und bewog den Sorbenfürsten Derwan zum AnschluB. Aus diesen Angaben schlo $B$ man, daB Samo Nachbar der Franken, Alemannen, Thüringer und Sorben gewesen sei und trachtete nun, nach solchen geographischen Beziehungen die Lage seines Reiches zu bestimmen. Das führte endlich dazu, daß es Nemeček an die Grenze Thüringens ${ }^{3}$ ), Peisker nach Oberfranken verlegte ${ }^{4}$ ), beide aber Samo als Herren der Čechen entthronten und nur zum Häuptling eines kleinen Slawengaues im Deutschen Mittelgebirge machten. Macht man sich diese Ansicht zu eigen, hält man also alles für Täuschuug, was Fredegar und die Conversio über Samos KarantanerHerrschaft scheinbar sagen, so gibt man aber auch den einzigen quellenmäßigen Beleg dafür preis, daß sich zu Beginn des 7. Jahrhunderts alle Karantaner von den Awaren befreit hätten und man müßte unter solchen Umständen sofort gestehen, über die Beziehungen beider Völker zueinander von Samos Zeit bis in die Mitte des 8. Jahrhunderts überhaupt nichts zu wissen.

1) Kaemmel, Die Anfänge deutschen Lebens in Österreich S. $185 \mathrm{f}$.

2) Goll, Samo und die karantanischen Slawen; Mitteilungen des Instituts für österreiche Geschichtsforschung Bd. 11 S. $443 \mathrm{ff}$.

s) Němeček, Das Reich des Slawenfürsten Samo. Jahresbericht der Landesoberrealschule in Mährisch-Ostrau 1905/6. - Stur, Die slawischen Sprachelemente in den Ortsnamen der deutsch-österreichischen Alpenländer. (Sitzungsber. d. k. Akad. d. Wiss. in Wien phil.-hist. Kl. Bd. 176, S. 14 ff.) schlieBt sich den Ausführungen Nèmeřeks glatt an.

4) Peisker, Neuc Grundlagen der slawischen Altertumskunde S. 8. 
Allein, ist diese gänzliche Abkehr von den geschriebenen Quellen begründet? Ist die Art der Kritik, die zu so grenzenlosem Mißtrauen geführt hat, auch methodisch einwandfrei? Um darüber zu entscheiden, stellen wir zunächst die umstrittenen Quellenabschnitte zusammen:

Conversio cap. 4.

Temporibus-Dagoberti Samo nomine quidam Sclavus manens in Quarantanis fuit dux gentis illius. Qui venientes negotiatores Dagoberti regis interficere iussit et regia expoliavit pecunia. Quod dum conperit Dagobertus rex, misit exercitum suum et damnum quod ei idem Samo fecit, vindicare iussit. Sicuti fecerunt, qui ab eo missi sunt et regis servitio subdiderunt illos.

Da die Conversio nach ihren eigenen Worten ältere Quellen verwertet hat, so genügt die Übereinstimmung der gesperrt gedruckten Wörter, um zu erkennen, daß der Salzburger Schreiber hier Fredegar benützt hat. Unsicher ist nur, wie stark. Goll, der diese Übereinstimmung zuerst aufgedeckt hat, meint, in Karantanien habe man von Samo überhaupt nichts gewußt; was die Conversio über ihn bringe, sei ausschließlich aus Fredegar geschöpft 1). „Denn durch die Verbindung Samos mit den karantanischen Slawen sollte deren Zugehörigkeit zum fränkischen Reiche und damit zur Salzburger Kirche bewiesen werden.

1) Goll a. a. O. S. 444 . 
Deshalb habe auch hier Samo von den Franken besiegt werden müssen, während er bei Fredegar siegt 1). Die Nachricht der Conversio über Samo sei daher nur eine leere Geschichtsklitterung aus der Zeit der kirchenpolitischen Kämpfe Salzburgs mit Method. Allein, hat denn so muß man sich angesichts solcher Vorwürfe fragen - die Conversio an Fredegars Kriegsbericht überhaupt ełwas eigenmächtig verdreht? Dort steht doch ausdrücklich, daß die Slawen zwar bei Wogastisburg über die Austrasier siegten, dafür aber auf den beiden andren Kriegsschauplätzen gegen Alemannen und Langobarden unterlagen. Es war also mindestens gleich richtig von einem Siege wie von einer Niederlage Sdmos zu sprechen. Wer aber, wie der Salzburger Schreiber in Samo einen Karantanerfürsten erblickte, der durfte sogar aus Fredegar nichts andres entnehmen, als die Niederlage Samos. Denn dann waren dessen Hauptgegner die Langoborden gewesen und gerade die hatten entscheidend gesiegt.

Übrigens hatte der Verfasser der Conversio vielleicht nicht einmal einen Anlaß, zwischen Sieg und Niederlage zu wählen. Die Gesta Dagoberti z. B., die den Krieg gegen die Wenden mit den Worten Fredegars erzählen, übergehen die unglücklichen Kämpfe der Franken bei Wogastisburg mit völligem Schweigen ${ }^{2}$ ) und verzeichnen nur die großen Erfolge der Alemannen und Langobarden, weil es offenbar dem austrasischen Verfasser widerstrebte, die Schmach seiner Landsleute einzugestehen. Wenn die Conversio ihre Kenntnis des Wendenkrieges. aus einer solchen abgeleiteten Quelle schöpfte, wußte sie überhaupt nichts von einem Siege Samos und konnte schon deswegen nur von einer Unterwerfung reden. Auf keinen Fall hat mau demnach das Recht zu behaupten, die Conversio habe Fredegars Kampfbericht mit Absicht entstellt.

Nicht besser steht es um den Versuch, den Zweck der Conversio auch dafür verantwortlich zu machen, daß in ihr Samo, der Franke, auf einmal als Slawe erscheint ${ }^{3}$ ). Oder konnte etwa Salzburg saine Ansprüche auf Karantanien besser begründen, wenn es Samo zum Slowenen verfälschte? Gerade wer ihn nur deshalb anführte, um mit: ihm geschichtliche Rechte der Salzburger Kirche zu erhärten, hätte sich strengstens an Fredegar halten müssen. Er hätte dann nicht nur die fränkische Herkunft seines Helden sorgfältig unterstrichen, sondern auch nicht versäumt, mit besonderem Nachdruck dessen Worte zu

1) Nĕmeček a. a. O. S. 3.

2) Mon. Germ. SS. rer. Meroving. Bd. II S. 410.

s) Goll a. a. O. S. 444. 
wiederholen, daß sein Reich Dagoberts Eigentum sei. Schon damals $\left.{ }^{1}\right)$ - so hätte dann der Schreiber der Conversio sagen können - war Karantanien den Franken unterworfen gewesen, daher gebührte dort unbestreitbar der Vorrang vor dem Byzantiner Method dem Erzbischofe von Salzburg als Angehörigem des fränkischen Reiches. Der Zweck der Conversio hätte somit alles eher verlangt als daß man Samo zum Slowenen stempelte. Wenn ihn die Salzburger Streitschrift trotzdem slowenischen Stammes nannte, so tat sie es gewiß in gutem Glauben, offenbar deshalb, weil er in der dunklen Erinnerung der Karantaner als Slawe fortlebte.

Die Salzburger Mel dung über Samo hat man sich daher wohl folgendermaßen entstanden zu denken: Der Verfasser der Streitschrift gegen Method übernahm aus dem Volksmunde die Nachricht von einem alten Karantanerfürsten namens Samo. Da dieser laut Fredegar oder einer aus ihm abgeleiteten Quelle mit den Franken gekämpft hatte, so verknüpfte man beide Angaben, jedoch nicht ohne sich dabei mit Fredegar kritisch auseinand erzusetzen. Denn daß sich die Slowenen einen Franken zum Herrscher erhoben hätten, dünkte den Salzburger doch gar zu unwahrscheinlich. Lieber traute er der volkstümlichen Überlieferung und fügte daher gleichsam berichtigend Samos Namen die sonst wohl überflüssige, weil selbstverständliche Bemerkung bei: „ein Slawe".

Es ist sehr lehrreich zu sehen, daß es Jahrhunderte später dem Ungarnkönig Mathias Corvinus nicht anders erging als Samo. Die Türkennot des 15. Jahrhunderts brachte Slowenen und Ungarn einander nahe; und wie einst Samo als Schirmherr gegen die Awaren, so wurde damals Mathias Corvinus als Türkenbezwinger dem slowenischen Volke vertraut. Da er zudem in den Kämpfen mit Kaiser Friedrich III. einen großen Teil der österreichischen Alpenländer, darunter auch slowenisches Gebiet, besetzte, so drängte er sich dem Denken und Fühlen des slowenischen Volkes so stark anf, daß sich Volkslied und Sage seiner bemächtigten und aus dem Ungarnkönig einen slow enischen Volkshelden, den kralj Matjaž, machten, ja, daß ihn die Kärntner Sage sogar nach altehrwürdiger Sitte auf dem Zollfeld zum König erwählt sein ließ (Gruden, Zgodovina slovenskega naroda S. 377 f.). Das Gegenstück zu Samo, das die slowenische Sage in kralj Matjǎ bietet, erhärtet so aufs Beste die Eirgebnisse unserer Quellenkritik, nach denen die Ansichten Golls und Němečeks, soweit die Conversio in Betracht kommt, rundweg abzulehnen sind.

1) Fredegarii Chronicon IV cap. 68: „Et terra, quan habemus, Dagoberto est et nos sui sumus". 
Beide wollen jedoch auch an Fredegar deuteln und namentlich Němeček meint, aus Fredegar lasse sich Samos Herrschaft über die Karantaner nicht beweisen. Man müßte zwar an sie glauben, wenn Dagobert wirklich zum Wendenzuge die Nachbarn der Karantaner, die Langobarden, aufgeboten hätte; allein das sei nicht wahr. Die Langobarden hätten sich darau gar nicht beteiligt 1). Nèmeček beruft. sich dabei auf Schnürer. Dieser stellt nämlich in seiner Untersuchung über "die Verfasser der sogenannten Fredegar- Chronik" fest, daß der zweite Schreiber, ein Burgunder, aus dem Munde eines fränkischen Gesandten über die Langobarden Nachrichten empfing, die er zeitlich gar nicht oder nur willkürlich anzusetzen wußte 2). Im Anschluß daran behauptet nun Němeček ${ }^{3}$ ): „Der burgundische Chronist hörte von Kämpfen der Franken mit den Langobarden, hörte sie vielleicht mit der Person Dagoberts verknüpfen und führte sie in gewohnter Weise bei der passendsten Gelegenheit an, in diesem Falle in dem Berichte über die Slawen im Osten".

Wir lassen es dahingestellt, ob es die passendste Gelegenheit ist, einen angeblichen Kampf der Franken gegen die Langobarden dort unterzubringen, wo aus ihm des Zusammenhanges halber ein gemeinsamer Kampf beider Völker mit den Slawen werden muß. Auch abgesehen davon ist Němečeks Ansicht verfehlt, da sie die Darstellungsweise Fredegars nicht genügend beachtet. Man hat nämlich unter den außerfränkischen Nachrichten zu unterscheiden zwischen kurzen Angaben, die in die fränkische Geschichte sinngemäß verwoben sind und längeren Abschnitten, die der Schreiber rein äußerlich ohne Zusammenhang eingeschoben hat. Zum Beispiel:

In cap. 68 wird, wie wir schon wissen, ausführlich Dagoberts Feldzug gegen Samo besprochen und nur nebenbei kurz der Waffenhilfe der Langobarden gedacht; die unmittelbar folgenden Kapitel 69-71 dagegen behandeln durchwegs langobardische Geschichte und zwar vom Ende der Regierung Arioalds bis zur Befreiung der Königin Gundoberga. Nur mit Bezug auf diesen Überblick behauptet Schnürer, „daß es dem Verfasser an jedem Maßstabe für die Fixierung der Ereignisse gefehlt habe, daß er sie zuletzt unter bestimmte Jahre nur eingereiht habe, um sie irgendwo unterzubringen, ohne sein Annalenschema aufgeben zu müssen" ${ }^{4}$ ). Wenn daher Němeček im Gegensatze

1) Nèmeček a. a. O. S. $3 \mathrm{f}$.

2) Schnürer, Die Verfasser der Fredegar-Chronik. Collectanea Friburgensia Heft 9 S. 115.

8) Němeček a. a. O. S. 4.

4) Schnürer a. a. O. S. 115 . 
zu seinem Gewährsmann auch jener Einzelangabe über die Heeresfolge der Langobarden Unwahrheit vorwirft trotz ihrer logisehen Verbindung mit dem übrigen Inhalte des Kapitels, so hätte er vor allem versuchen müssen, seine leicht hingeworfene Behsuptung irgendwie zu begründen. Freilich wäre er dann rasch innegeworden, daß es dafür eine Begründung nicht gibt.

Man stelle sich doch den Sachverhalt vor! Ein Burgunder, der über die Taten der Franken schreibt, schaltet mitten in diese Erzählung plötzlich einen langen Abriß langobardischer Geschichte ein (cap. 69-71). Nur die eine knappe Nachricht über den Kampf der Langobarden mit den Wenden bringt er nicht, wie man erwarten möchte, in jener Zusammenfassung, sondern verflicht sie in das vorhergehende cap. 68 . Will man in dieser Vorwegnahme unbedingt eine Eigenmächtigkeit des Verfassers sehen und nicht lieber glauben, daß damals eben wirklich Franken und Langobarden gemeinsam gegen die Wenden gefochten haben, so könnte man eine solche Willkür höchstens damit erklären, daß es der Schreiber getan habe, um für die Reihe der ab cap. 69 mitgeteilten langobardischen Ereignisse eine Anknüpfung zu finden, daß er also Geschichtsfälscher aus Stilgefühl sei. Daran ist jedoch nicht zu denken. Denn wo steht die Langobardennachricht und wie viel später folgt erst, cap. 69! Beide trennt die Erzählung über die Schlacht bei Wogastisburg, die Kämpfe in Thüringen und der Anschluß des Sorbenfürsten Dervan an Samo, sodaß der Abrilß der Langobardengeschichte ganz unvermittelt einsetzen muß, von einem stilistischen Übergang gar keine Rede sein kann. Der einzige Beweisgrund, der für Němeček spräche, ist damit abgetan und es läßt sich jetzt vielmehr dartun, daß jene in cap. 68 eingestreute Bemerkung über die Teilnahme der Langobarden an Dagoberts Feldzug gegen Samo durchaus Glauben verdient.

In cap. 69-71 setzt nämlich der Burgunder nur fort, was er über die Langobarden schon in den Abschnitten 49-51 :zu erzïhlen begonnen hat 1). Diese teilen Ereignisse von ungefähr 600 bis in die Zeit Arioalds mit, dann bricht die Darstellung der Langobardengeschichte mitten in der Regierung Arioalds ab (cap. 51) und erst cap. 69 berichtet darauf über den Schluß der Herrschaft Arioalds und die ihr folgenden Ereignisse. Woher dieser sonderbare Riß? Die Erklärung liegt in cap. 68, das den fränkisch-langobardischen Krieg mit Samo erwähnt. Offenbar wußte der Schrejber, daß der Wendenzug der Langobarden nicht nur in die Zeit Arioalds falle, sondern auch in die

1) Schnürer a. a. O. S. 114. 
Geschichte der Franken hineinspiele und daher dort seinen Platz haben müsse. Mit andren Worten, nicht weil der Chronist seine Znsammenfassung langobardischer Geschichte geschmackvoll unterbringen wollte, riß er die nach Němeček undatierbare Einzelangabe über den Kampf der Langobarden mit den Slawen heraus und stellte sie voran, sondern umgekehrt, weil ihm die Einzelangabe schon in einer fertigen Tatsachengruppe vorlag, zerriß er die Zusammenfassung. Damit fallen die Schlüsse, die Němeček aus cap. 68 gezogen hat. Samos Herrschaft über die Karantaner und ihr Kampf mit den Langobarden sind daraus nicht mehr hinwegzudenken.

Hätte Němeček nicht wie gebannt immer nur diese eine Stelle im Auge gehabt, so wäre es ihm gewiß nicht entgangen, daß ihr Inhalt auch von andrer Seite bestätigt wird. Nach Fredegars Kap. 72 zum Beispiel gebot Walluk über eine Mark, d. h. nach dem Sprachgebrauch jener Zeit über ein abhängiges Grenzland und nicht ein selbständiges Reich 1). Von wem hätte aber damals sein Land abhängig sein sollen, wenn nicht von Samo? Außerdem erscheint Walluk in derselben Quelle als Herzog der Wenden, Samo dagegen als ihr König. Wenn man beachtet, wie genau Fredegar aus den fränkischen Verhältnissen die Stellung der Herzoge unter dem Könige kannte ${ }^{2}$ ), so ist man gezwungen zu glauben, er habe Walluk und Samo gerade wegen eines ähnlichen Rangsuntersehiedes einander als dux und rex gegenübergestellt. Ja selbst die Niederlage, die die Slowenen 631 angeblich im Kampfe mit den Langobarden erlitten, ist unabhängig von Fredegar bezeugt. Denn wie Hartmann mit Recht sagt, ist es nicht einzusehen, warum man sich sträuben sollte, auf sie die Nachricht des Paulus Diaconus zu beziehen, daß Taso und Chaco von Friaul, deren Vater um 610 von den Awaren erschlagen worden war, "später“ ein Stïck slowenischen Landes erobert hätten ${ }^{3}$.

Besonders lebrreich aber ist das, was Fredegars Kap. 58 enthält. Darin liest man, 629 hätten die Germanenstämme, die an der awarischslawischen Grenze saßen, Dagobert, ihren Herrn, gebeten, ,die Awaren, Slawen und die übriłen Völker bis an die Grenze des byzantinischen Reiches zu unterwerfen ". Nun aber mache man sich klar: 629 forderten die von den Franken abhängigen Germanen Dagobert auf, ihre Nachbarn im Osten zu bekriegen, und zwei Jahre darauf 631 soll

1) Waitz, Verfassungsgeschichte Bd. $2^{3}$ S. $384 \mathrm{ft} ., 3$ S. $341 \mathrm{ff}$; Brunner, Rechtsgeschichte 2 S. 141; Schröder, Rechtsgeschichte 4 S. 119 ff.

2) Vgl. Fredegarii Chronicon, Register unter den betreffenden Schlagworten.

3) Pauli diaconi Historia Langob. IV cap. 38. - Hartmann, Geschichte Italiens Bd. II ${ }^{1}$, S. 211 , S. 236 n. 9. 
Dagobert mit drei Heeren wirklich die Westslawen Samos überfallen haben. Niemand kann übersehen, daß heide Ereignisse in ursächlichem Zusammenhang stehen, daß sich beide Nachrichten gegenseitig stützen. Die von 629 lehrt, daß das Unternehmen von 631 in der Tat nicht ein einfacher Strafzug gegen einen unbedeutenden Grenzhäuptling, sondern ein großangelegter Reichskrieg war, und die von 631 beweist, daß man 629 nicht aus Landhunger und Eroberungssucht zum Kriege trieb, sondern weil man mit Unbehagen sah, wie sich in den Kämpfen mit den Awaren eine große Slawenmacht zusammenballte, von der für die Zukunft schwere Gefahren drohten. In einen solchen Krieg aber paßte ein Angriff der Langobarden auf die Slowenen sehr gut hinein. Denn wenn man alle Slawen bis an die Grenze von Byzanz unterjochen sollte, konnte man gerade die Hilfe der Langobarden nicht missen, der einzigen Germanen, die bis an den Saum des oströmischen Reiches wohnten. Nur sie waren imstande, einen Teil der samonischen Slawen im Süden zu binden und so die Angreifer im Norden zu entlasten; ihre einzig möglichen Gegner aber waren in diesem Fall die Slowenen. In neubestärktem Vertrauen auf Fredegar und die Conversio darf man daher jetzt zusammenfassend sagen:

Als sich ein slawischer Starnm unweit der fränkischen Grenze gegen die Avaren erhob, schwang sich Samo zu dessen Führer im Freiheitskriege auf. Wahrscheinlich, weil dieser Kampf starke Kräfte der Awaren im Norden festhielt, nahmen die Alpenslawen die Gunst des Augenblicks wahr und griffen auch zu den Waffen wider ihre Bedrücker. Der Haß gegen den gemeinsamen Feind aber führte die Empörer bald zusammen und so kam es, daß schon 629 die Umrisse einer westslawischen Großmacht sichtbar waren. Als nun zwei Jahre später Dagobert gegen dieses neue politische Gebilde einen umfassenden Angriff unternahm, erlagen zwar die Slowenen den Langobarden und verloren einen Teil ihres Gebietes, dafür aber schlug Samo das aus Franken gebildete Hauptheer. Der Glanz seiner Taten bewog darauf den Sorbenfürsten Dervan, ihn freiwillig als seinen Herrn anzuerkennen, sodaß Samo schließlich die westslawischen Völkerschaften von der Saale bis herab zur Wendenmark Walluks unter seinem Szepter vereinte. Freilich war das, was er beherrschte, kein festgefügtes Reich, sondern ähnlich wie der Markomannenstaat Marbods oder das Gotenreich Ermanrichs nur ein lockerer Bund, der mit der überragenden Patriarchengestalt seines Gründers stand und fiel.

Über die Zeit, wann dieses samonische Großreich bestanden haben soll, ist man sich nicht recht klar. Aus Fredegars Kapitel 48 erfährt man, Samo sei im 40. Regierungsjahre des Frankenkönigs Chlotar, 
d. i. 623, zu den Wenden gekommen und habe fünfunddreißig Jahre über sie geherrscht. Nimmt. man, was wahrscheinlich ist, an, daß seiner Ankunft bei den Slawen noch im selben Jahre die Wahl zum König gefolgt sei, so ergibt sich daraus für seine Regierung die Zeit von 623-658. Da aber das Kapitel 48 vom zweiten Verfasser der Fredegarschronik einem Burgunder, stammt, der 642 schrieb 1), so scheint dieser Ansatz unbedingt falsch zu sein. Krusch und Schnürer glauben ein Mittel gefunden zu haben, um hier Klarheit zu schaffen. Sie berufen sich nämlich auf die Unzuverlässigkeit Fredegars in der Datierung außerfränkischer Nachrichten und erklären das vierzigste Jahr Chlotars nur für ein willkürliches Datum, „das es ermöglichen soll, den Bericht über Samo äußerlich in das Annalenschema einzureihen". Uns stünde es dann frei, den Beginn der fünfunddreißigjährigen Herrschaft Samos von 623 ins erste Jahrzehnt des 7. Jahrhunderts zurückzuverschieben ${ }^{2}$ ). Allein es gibt noch eine viel einfachere Erklärung.

Das oben schon öfter erwähnte Kapitel 68, das den Krieg Dagoberts gegen Samo behandelt, rührt, wie Schnürer nachgewiesen hat, von demselben Burgunder her, der Kapitel 48 verfaßt hat; nur an einzelnen Stellen ist es nachträglich von einem dritten Schreiber, einem Austrasier, überarbeitet und ergänzt worden ${ }^{3}$ ). Da es aber bekannt is $\iota_{\text {, }}$ daß dieser 658 an der (hronik schrieb ${ }^{4}$ ), so ist der scheinbare Widerspruch in Kapitel 48 auch schon gelöst. Denn unwillkürlich rechnet man, $658-35=623$, und schließt dann weiter: wie in Kapitel 68 der Grundstock der Erzählung auf den Burgunder zurückgeht, so ist auch Kapitel 48 zwar in der Hauptsache von jenem niedergeschrieben, die Bemerkung über die Regierungsdauer Samos aher erst später als $\mathrm{Zusatz}$ von dem Austrasier angefügt worden. Die Thronbesteigung Samos ist daher für das. Jahr 623 doppelt verbürgt: durch den Burgunder, der sie mit Hilfe der Regierungsjahre Chlotars datiert und durch den Austrasier, nach dessen Angaljen man sie rückzählend ebenfalls auf 623 ansetzen muß. Damit ist aber auch Samos Regierungszeit für die Jahre 623-658 außer Frage gestellt und nur das eine will noch erörtert sein, ob sich

1) Krusch, Die Chronicie des sogenannten Fredegar S. 4. Neues Archiv der Gesellschaft für ältere deutsche Geschichtskunde Bd. 7, S. 429. - Schnürer a. a. O. S. 89,112 .

2) Krusch a. a. O. s. $434 \mathrm{f}$. - Schnürer a. a. O. S. 113.

s) Schnürer a. a. O. S. 111.

4) Krusch a. a. O. S. 429, 443. - Schnürer a. a. O. S. 89. 
damals alle Slowenen oder nur ein Teil von ihnen der awarischen Herrschaft entwunden haben.

Die beiden Hauptquellen lassen uns leider bei dieser Untersuchung fast ganz im Stich. Fredegar sagt überhaupt nicht, von welchen Slowenen er spricht und die Conversio meldet nur kurz, Samo sei Herr der Karantaner gewesen. Der Klang des Wortes läßt bei Karantaner an Kärnten denken und in der Tat gibt es keinen einzigen Beleg, daß man vor dem 8. und 9. Juhrhundert darunter auch die Bewohner des östlichen und südöstlichen Vorlandes von Kärnten verstanden hätte; die bekamen diesen Namen vielmehr nachweislich erst infolge der politischen Entwicklung der bayrisch-fränkischen Zeit 1). Nimmt man die Conversio wörtlich, so hätten sich daher im 7. Jahrhundert nur die Kärntner-Slowenen von den Awaren befreit. Doch dem widersprechen Tatsachen der kroatischen Geschichte.

Nach eingehenden sprachlichen und geschichtlichen Forschungen steht es fest, da $B$ sich die Vorfahren der heutigen Kroaten und Serben nicht erst, wie man früher glaubte, unter Kaiser Heraklius (610-641) in ihren gegenwärtigen Sitzen niederließen, sondern schon seit Beginn des 6. Jahrhunderts, nach Niederle sogar seit dem. 3. Jahrhundert in stetem Vorrücken über Drau und Sawe nach Süden begriffen waren und bereits 548 das erstemal die Meeresküste erreichten ${ }^{2}$ ). Welle um Welle fluteten die Südslawen über den Karst, unter ihnen auch der Stamm der Kroaten. Diese siedelten sich besonders dicht in Mitteldalmatien, dem Hinterlande von Spalato, an. Dank dem kriegerischen Geiste, der sie beseelte, und der sich im Freiheitskriege gegen die Awaren unter Kaiser Heraklius glänzend bewährte, gelang es ihnen, sich in Dalmatien eine Herrenstellung zu schaffen und hier den Grund zu ihrem später so mächtigen Staate zu legen ${ }^{3}$ ).

Diese reichsgründende Kraft blieb ihnen auch an andrer Stelle treu. Denn nach der Vertreibung der Awaren "löste sich von den nach Dalmatien gekommenen Kroaten ein Teil los und richtete in

1) Vgl. unten S. 266 ff., 273

2) Rački, Biela Hrvatska ì Biela Srbija (Rad jugoslavenske akademije Bd. 52, S. $141 \mathrm{ff}$. und Bd. 59 S. $201 \mathrm{ff}$ - - Jagić, Ein Kapitel aus der Geschichte der südslawischen Sprachen (Archiv für slawische Philologie Bd. 17 S. 47 ff.) - Niederle, Slovanské starozitnosti Bd. 2 S. $244 \mathrm{ff}$., $278 \mathrm{ff}$.

s) Dümmler, Über die älteste Geschichte der Slawen in Dalmatien (Sitzungsbe:ichte der k. Akademie der Wissenschaften in Wien, Bd. 20 S. 3ã3). - Klaić, Poviest Hrvata Bd. 1 S. 30. - Niederle a. a. 0. Bd. 2 S. 386 ff. - Die Geschichte der kroatischen Wanderungen und ihrer sozialen Folgen wird seinerzeit Gegenstand einer zusammenhängenden Untersuchung sein. 
Pannonien seine Herrschaft auf ${ }^{1}$ ). Da die soeben noch siegreichen Kroaten gewiß nicht ins 7wischenstromland zwischen Drau und Sawe hinabgestiegen wären, wenn sie dort wieder die awarische Hoheit hätten aut sich nehmen müssen, so bedeuten jene Worte des Koustantin Porphyrogennetos, daß damals die Awaren bis hinter die Drau zurückwichen und die von ihnen bisher beherrșchten Slowenen des SaweKulpabeckens den Kroaten preisgaben.

Nur Sirmien dürften sie behauptet oder doch bald wieder besetzt haben, um sich den Weg nach Ostrom frei zu halten ${ }^{2}$ ). Der Besitz des Barbarenlandes in der Mulde von Sissek dagegen war ihnen keine besonderen Opfer mehr wert. Hier mochten die Kroaten herrschen, awarisches Blut war für solchen Preis nicht mehr feil, seitdem es unter den Streichen der aufständischen Slawen in Strömen geflossen war.

Die Anfänge zur Staatenbildung auf dem Boden des Fürstentums Sissek, das zu Ludwig des Frommen Zeiten den Franken so furchtbar werden sollte ${ }^{3}$ ), hingen also mit dem Vorstoß der Kroaten beim Sturz der awarischen Großmacht im 7. Jahrhundert zusammen.

Die Wanderung der Kroaten kan aber auch in Pannonien, an der Drau, noch nicht zum stehen. Die obelı nur gekürzt wiedergegebene Stelle aus Konstantin Porphyrogennetos besagt vielmehr in ihrem vollen Wortlaut, daß sich ein Teil der dalmatinischen Kroaten ,in Pannonien und Illy rien seine Herrschaft aufgerichtet habe". Welche Gegend mit Illyrien gemeint sei, darüber hat man allerdings die verschiedensten Vermutungen geäußert. Wenn die Stelle nicht verderbt ist, so kann die einzig richtige Erklärung wohl nur die sein, daß man darunter Noricum zu verstehen habe. Schon bei der Begründung ihrer Herrschaft in den Donauländern hatter die Römer Noricum und Pannonien zu Illyrien geschlagen und trotz manchen Schwankens in der Verwaltungsordnung erhielt sich diese Beziehung Noricums zu Illyrien so stark, daß man seit dem siegreichen Gotenkriege Justinians wieder Noricum neben Pannonien, Dalmatien und Obermösien zu Mlyrien rechnete ${ }^{4}$ ). Da nun Obermösien und Ostdalmatien serbisch,

1) Konstantin Porphyrogennetos, De administrando imperio cap. 30. Bonner Ausgabe von Becker.

2) 758 wenigstens war Sirmien sicher awarisch. Denn aus dieser Zeit hört man von einem Fürsten Kuber, der als Vasall der Awaren hjer herrschte: Rački, Documenta historiae chorvaticae periodam antiquam illustrantia S. 292 ff. - dazu Rački, Hrvatska prije XII. vieka (Rad jugoslav, akademije Bd. 56, S. 104).

3) Annales regni franc. ad a. 819-822.

4) Marquart, Römische Staatsverfassung I S. 138; Kämmel, Anfänge deutschen Lebens S. 46 f., 107, 134 f.; Katalivich, Storia della Dalmazia II, 154. 
Pannonien nördlich der Drau awarisch war, so bleibt eigentlich nur Noricum als jenes Illyrien übrig, in das Kroatən aus Dalmatien eingewandert sein können ${ }^{1}$ ). Doch auch wer die Nachricht des kaiserlichen Gewährmannes ganz verwirft, wird an den Zuzug kroatischer Siedler nach Noricum glauben müssen, wenn er die Ortsnamenkunde zu Rate zieht. Denn er findet in Steiermark ein altes Chrawate als Bezeichnung für eine Gegend bei Gonowitz, ein Kraubat im Flußgebiete der Lasnitz, ein Krabaten und Krabersdorf, einst Chrawaczdorf, bei Gleichenberg und endlich ein Krowot südöstlich von Weitz ${ }^{2}$ ). Mit unverkennbarer Deutlichkeit stellen doch diese vier mittel- und untersteirischen Namen die Brücke her zwischen den Kroatensiedlungen im pannonischen Zwischenstromlande und denen in Kärnten. Über Unter- und Mittelsteiermark müssen also die Kroaten nach Kärnten gedrungen sein, erst hier war ihre Wanderung zu Ende. Hat man einmal diese Tatsache erfaßt, so blitzt aber auch unwillkürlich der Gedanke auf, die Kroaten bätten, wie den Slowenen Unterpannoniens, so auch denen in Karantanien staatliche Ordnung gebracht, mit andren Worten, Walluks „Wendenmark " sei eine kroatische Schöpfung gewesen. In der Tat ist die Herrschaft dieses Fürsten erst für eine Zeit bezeugt, die sich mit unsrer Annahme ohneweiters verträgt. Denn die Vernichtung der Awarenmacht in Dalmatien fällt zwischen 626 und 641 , während Walluk erst für etwa 650 nachzuweisen ist ${ }^{3}$ ).

Die Richtung der kroatischen Wanderung setzt nun voraus, daß sich zu Samos Zeit nicht nur die Karantaner die Unabhängigkeit errungen haben, sondern ebenso auch die Slowenen von Untersteier und Krain. Ohne deren Teilnahme am großen Freiheitskriege der Slawen hätte sich ja fortan ein Keil awarischer Macht zwischen Kroatien und Kärnten eingeschoben und wie ein Staudamm jedes Abfließen kroatischen Volkstums nach Nordwesten gehindert. Daß die awarische Herrschaft um 630 auch unter den Slowenen an der Sawe dahin gewesen sein $\mathrm{muB}$, das wird man übrigens jetzt nach diesen geschichtlichen Zeugnissen auch aus militärisch-geographischen Gründen gern für selbstverständlich erklären. Denn es ist ganz undenkbàr, daß in einer Zzit, wo sich Slawen und Bulgaren im Westen, Süden und Südosten gegen die Awaren erhoben, diese die Zeit und Kraft gefun den häiten, sich mitten in diesem brandenden Völkermeer einen schmalen

1) Schafarik a. a. O. II S. 279 . - Katalinich a. a. O., II S. $154 \mathrm{f}$.

2) Zahn, Ortsnamenbuch S. 111, 113, 118.

3) Die Ereignisse von Fredegars cap. 72, des einzigen, in dem von Walluk die Rede ist, fallen, wie Krusch bewiesen hat (vgl. seine Ausgabe Mon. Germ. SS. rer. Meroving. II S. 157 n. 3) in die Zeit des Kaisers Konstans II. (641-668). 
Steg nach Italien zu retten, d. h. gerade Untersteiermark-Krain zu behaupten.

Freilich kann dieses Gebiet nicht lange unabhängig geblieben sein. Paulus Diaconus erzählt nämlich, um 663 habe der langobardische König Grimoald gegen den Empörer Lupus von Friaul den Chagan der Awaren zu Hilfe gerufen und dem sei es in einer viertätigen. Schlacht gelungen, die Friauler zu werfen und Lupus zu töten. Des Ermordeten Sohn Arnefrit sei dann zu den Karantanern geflohen, um mit ihrer Unterstützung sein Herzogtum zurückzuerobern ${ }^{1}$ ).

Auf den ersten Blick scheint diese Geschichte nicht die leiseste Andeutung über die politische Stellung von Untersteiermark-Krain zu enthalten; bei einiger Überlegung aber zeigt sich das Gegenteil. Denn warum wandte sich Arnefrit nicht lieber an die Krainer als an die Karantaner? Der Politik der Karantaner gab ja die Drau die Richtung an und die wies nach Westen, gegen Bayern; mit Oberitalien war die Berührung so schwach, daß der Langobarde Paulus Diaconus wohl von lebhaften Kämpfen der Karantaner mit B ay ern ${ }^{2}$ ), aber nicht mit seinen Landsleuten zu melden weiß. Das Gegenteil gilt von den Krainern. Immer wieder stießen diese von den Höhen des Karstes in so hellen Hanfen bald als Freunde bald als Feinde nach Friaul vor ${ }^{3}$ ), daß Krain den Langobarden recht eigentlich als die „Heimat der Slawen" erschien ${ }^{4}$ ). Gerade nach dem Tode des Lupus brachen sie denn auch neuerdings in Oberitalien ein ${ }^{5}$ ) und ließen seither ihre südwestlichen Nachbarn am Po bis tief in das 8. Jahrhundert nicht mehr zu Atem kommen. Warum wandte sich also Arnefrit nicht an die Krainer, diese Erbfeinde der Longobarden?

Man kann das erst begreifen, wenn man, von Zeit und Ort absehend, sich nư ans nackte Tatsachengerippe hält. Dann schätzt man: Ein landflüchtiger Fürst will sich von zwei Nachbarn einen als Bundesgenossen gewinnen, um durch ibn wieder auf seinen Thron zu gelangen. Während aber der eine der beiden bisher zum Lande des Vertriebenen fast keine Beziehungen hatte und nach einer ganz andren Richtung in Anspruch genommen war, liegt der zweite schon lange auf der Lauer und wartet nur auf den Augenblick, um loszuschlagen. Wen wird der Flüchtige wählen? Gewiß den zweiten, den ersten nur

1) Pauli diaconi Historia Langob. V cap. 18-22.

2) Ebenda IV cap. 7, 10, 39, V cap. 22. $45,51 \mathrm{f}$.

3) Ebenda IV cap. 12, 20, 24, 28, 37 f.; V. cap. 17 ff., 23; VI cap. 24,

4) Ebenda VI cap. 52: in Carniolam, Sclavorum patriam; vgl. auch. cap. 51 .

5) Ebenda $V$ cap. 23. 
dann, wenn jener nicht zu haben. Das hieße aber, auf unsren Fall übertragen, Arnefrit hätte sich an die Krainer wenden müssen. Wenn er es nicht tat, so fehlte für ihn die Wahlfreiheit, so kamen tür ihn von Anfang an nur die Karantaner in Betracht. Und warum? Ohne Zweifel deshalb, weil - das lehrt der ungehinderte Marsch der Awaren durch Untersteiermark-Krain im Jahre $663^{1}$ ) - die Slowenen an der Sawe schon wieder den Awaren gehorchten und es von Arnefrit daher Wahnsinn gewesen wäre, zu denen zu fliehen, deren Herren soeben seinen Vater getötet hatten.

Erst diese Feststellung beseitigt den Widerspruch, an dem bisher die Darstellung der awarisch-slowenischen Geschichte litt. Denn daraus, daB 610 der Chagan an der Spitze seines Heeres ungestört durch Untersteierwark-Krain nach Oberitalien ziehen konnte, schloß man mit Recht, dieses Gebiet habe damals unter awarischer Hoheit gestanden; nur den haargleichen Tatbestand von 663 hielt man für nichtssagend und erklärte die Krainer für frei, obwohl davon kein Wort in den Quellen steht. Will man al o mit ihnen in Einklang bleiben, so muß man bedingungslos anerkennen, daß die Slawen an der Sawe in der zweiten Hälfte des 7. Jahrhunderts von neuem unter awarische Herrschaft gerieten. Steht aber somit die politische Spaltung des slowenischen Volkes für diese Zeit fest, so wird man ibre leisen Anfänge, eingedenk unsrer früher geographisch abgeleiteten Annahmez), gern noch weiter zurück, vor Samo, verlegen und sich sagen: nur deshalb glückte es gerade in Kärnten, die awarische Herrschaft dauernd abzuschütteln, weil sie dank den geographisch-militärischen Vorzügen Kärntens hier nie so fest gestanden hatte wie an der alten pannonischfriaulischen Heerstraße in Untersteiermark und Krain.

\section{Der Staat der Karantaner.}

Der Sturz der awarischen Macht in Karantanien brachte den dortigen Slawen mit der Unabhängigkeit nicht auch die Gleichheit, sondern half nur einem neuen Stande, den Edlingeru, in den Rung der Herrenschicht empor. Aus vereinzelten Nachrichten über diese Bevölkerungsklasse in Urbaren und Urkunden, dazu aus neun noch heute gebränchlichen Ortsnamen der Form Edling ${ }^{3}$ ) geht hervor, „daß

1) Vgl. oven S. 2508 n. 1.

2) Vgl. oben S. $243 \mathrm{f}$.

3! Jaksch, Über Ortsnimen und Ortsnamenforschung S. 36; Puntschart, Herzogseinsetzung und Huldigung in Kärnten S. 175 ff.; Lessiak, Edling-Kazaze (Carinthia 1 Jg. 163 S. 81). 
die Edlinger am dichtesten in jenen Gegenden siedelten, die den alten Kroatengau ausmachten, also in jenem Gau, in dem die Huldigungsstätte, Karnburg und das Zollfeld, sowie die Orte Blasendorf und Poggersdorf lagen, an denen der Herzogbauer sein Besitztum hatte. Und es ergibt sich weiter, daß diese Gegenden ungefähr die Mitte des Gebietes bilden, wo Edlinger in Kärnten saßen ${ }^{1}$ )"

Aus Zahus Ortsnamenbuch ersieht man, daß ein ähnlich auffälliger Zusammenhang zwischen Kroaten- und Edlingersitzen auch in Steiermark bestand. Bei Weiz stößt man auf ein Krowot und ein Edling, bei Leibnitz erwähnt Zahn ein Kraubat und eine Gegend namens Edelingen, dem Chrawate bei Gonobitz entspricht in der Umgebung von Cilli abgesehen von der Edlingergemeinde zu Tüchern ein Edling und ein Kassasse, die slowenische Bezeichnung für Edling, und an das Kraubat und Chrawat südwestlich von Leoben schließt sich Mur aufwärts über Murau gar eine ganze Reihe von Gehöft-, Dorf- und Gegendnamen, die auf eine Besiedlung durch Edlinger hinweisen.

Die Angehörigen dieses Standes waren freie slawische Bauern ${ }^{2}$ ), die ursprünglich auf eigenem Grunde, dem „Edeltum“, hausten. Allein mit der Zeit erging es ihnen ebenso wie den Freibauern Oberösterreichs. Diese ergaben sich bekanntlich an den Altar einer Kirche zum Pfennigdienst oder erwählten sich mächtige Herren zu Vögten. Während aber anfangs nocb das BewuBtsein lebendig blieb, daß sie den dafür gebührenden Dienst von ihrem Kopfe, nicht ihrem Grunde leisteten entarteten später Altarzins und Vogtrecht zum Grundzins, sodaB nur noch der Name "freies Eigen" und die leichte Belastung des Gutes davon zeugten, da $\beta$ dort einst ein freier Mann auf freiem Boden gelebt hatte ${ }^{3}$ ). Ähnlich hat man sich auch das Schicksal der Edlinger vorzustellen. Denn obwohl sie schon im späteren Mittelalter meistens nur Hintersassen waren, erinnerten doch selbst dann noch die stolze Bezeichnung ihres Anwesens als Edeltum und die geringe Abgabenpflicht, daß die Scholle, die sie bebauten, vor Zeiten ihr Eigentum gewesen war $^{4}$ ).

Schon Puntschart empfand aber, daß das ursprüngliche Eigentumsrecht am Besitze allein einen so hochtrabenden Titel wie Edlinger nicht rechtfertigen könne. Er verfiel daher auf den Gedanken, ihn

1) Puntschart a. a. O. S. 179.

2) Ebenda S. $200 \mathrm{f}$.

s) Hauptmann, Über den Ursprung von Erbleihen in Österreich, Steiermark und Kärnten S. 50 (Forschungen zur Verfassungs- und Verwaltungsgeschichte der Steiermark 8. Bd.).

4) Puntschart a. a. O. S. $181 \mathrm{ff}$., 186. 
mit dem Ausdruck nobilis in Beziehung zu bringen. Dieser Name bedeutete seit dem frühen Mittelalter im Allgemeinen den vollfreien Grundbesitzer, der deshalb in den Urkunden bald als nobilis, bald als liber oder mit Verstärkung des Titels als nobilis et liber erscheint ${ }^{1}$ ) Als aber unter dem Einflusse des Lehenwesens der Gegensatz von frei und unfrei allmählich verblaBte und sich die Gesellschaft dafür in einen Wehr- und Nährstand zu spalten begann, ging die Standesbezeichnung nobilis auf die durch ein Kriegslehen zu Reiterdienst verpflichteten Mannen, die Ritter im weitesten Sinne, über, gleichviel ob sie frei oder unfrei waren 2). Das „Steirische Landrecht" zählte denn auch selbst die niederen unfreien Ritter zu den Edlen ${ }^{3}$ ). „Angesichts dessen, meinte Puntschart, dürfen wir annehmen, daß in der Bezeichnung von Bauern als Edlinger ihr Waffenrecht zum Ausdruck kommen sollte" und mit besonderer Befriedigung wies er daher auf die Pflicht der Edlinger hin, die Burg zu verteidigen, zu der sie gehörten ${ }^{4}$ ).

Leider trägt diese scheinbar so glückliche Beweisführung schon den Gegenbeweis in sich. Denn nicht das Waffenrecht schlechtweg, sondern nur die Ritterbürtigkeit berechtigte dazu, sich edel zu nennen; ritterbürtig aber waren die Edlinger als Bauern nie. Das Grundwort ihres Namens auf diese Art zu erklären, ist mithin nicht erlaubt oder man müßte es für logisch halten zu schließen: A nennt man edel, weil er ritterbürtig ist und B, weil er - es nicht ist.

Vor Kurzem beschäftigte sich mit der Erklärung von "Edlinger * auch Lessiak. In seiner Abhandlung „Edling-Kazaze" wies er überzeugend nach, daß der slowenische Name für Edlinger, Kases, aus einem turkotatarischen quazaqu entstanden ist 5 ). Da aber dieses Wort noch heute in verschiedenen türkischen Sprachen den Freien bedeutet, so konnte es sich. sagt er treffend, von dieser Grundbedeutung aus sehr wohl zur Bezeichnung einer bevorzugten Bevölkerungsschicht entwickeln; und in der Tat hat, es diesen Weg eingeschlagen im Kleinrussischen, wo Kozak außer Kosak auch so viel wie Held, Freib auer besagt. In Anbetracht dessen, daß im früheren Mittelalter der Vollfreie als edel galt, käme also der Sinn des Wortes Kases dem von Edling "gleich, oder doch außerordentlich nahe " 6). Mit andren Worten,

1) Luschin, Österreichische Reichsgeschichte S. 230. - Huber-Dopsch, Österreichische Reichsgeschichte S. 50.

2) Schröder, Deutsche Rechtsgeschichte S. $438 \mathrm{ff}$.

3) Zallinger, Die ritterlichen Klassen im Steirischen Landrecht (Mitteilungen des Institutes für österreichische Geschichtsforschung IV S. $399 \mathrm{ff}$.).

4) Puntschart a. a. O. S. 197 f.

5) Lessiak a. a. O. S. 87.

в) Ebenda S. 88 .

Mitteilungen XXXVI. 
Lessiak faßt scheinbar „Edling“ als die getreue Übersetzung von Kases auf.

Doch auch das ist nicht sehr wahrscheinlich. Denn nach bayrischen Standesbegriffen zählten von den Freien nicht alle zu den Edlen, sondern nur die "Hochfreien" und die waren Grundherrn 1). Die Edlinger dagegen waren bescheidene Bauern, deren "Edeltum" nicht einmal die Größe einer gewöhnlichen Untertanshube zu erreichen brauchte, ja bei den Edlingern von Sagor nachweislich sogar nur die Hälfte davon ausmachte ${ }^{2}$ ). Hätten es die deutschen Zuwanderer als ihre Aufgabe erachtet, gerade Kases in Sinne von Freibauer wörtlich zu übersetzen, so wäre es ibnen wohl kaum eingefallen, dafür das Wort nobilis-edel zu verwenden und es hier einem Kleinbauern beizulegen, da sie doch von Haus aus gewohnt waren, es nur dem freien Grundherrn vorzubehalten.

$\mathrm{DaB}$ auf diese Weise der Name Edlinger schwerlich entstanden sein kann, bestätigt auch der lateinische Sprachgebrauch. In Urkunden des 13. Jahrhunderts tauchen bisweilen Bauern auf unter den Namen liberi und libertini. Während sich aber jene in den fünf überlieferten Beispielen als minderfreie Hintersassen, sogenannte Freileute, zu erkennen geben ${ }^{3}$, verbergen sich unter diesen, den libertini, außer Freileuten anch Bauern, die auf eigenem, frei verfügbarem Boden lebten und ihre Besitzklagen vor herzoglichen Richtern erhoben 4), alles Zeichen, daß sie freie Eigentümer waren. Da nun bei Johann von Viktring der Edlinger, der den Herzog einsetzte, rusticus libertus hieB, libertus und libertinus aber gleichwertige Ausdrücke sind, so kann man Puntschart nur beipflichten, wenn er in den auf Eigengrund sitzenden libertini Edlinger vermutet. Dagegen wird man ihm nicht beistimmen, wenn er in diesem Namen einen Bezug auf den angeblich edlen Rang ihrer Träger erblicken will. Denn - wir kommen wieder auf unsre frühere Bemerkung zurück - es war gar nicht jeder Freie ein Edler. Gewil, libertus konnte den Hoch- oder Edelfreien bedeuten - Puntschart führt selbst als Beweis eine Zeugenreihe un, wo es heißt: „Testes Perhtold comes de Tierols, Hartwic de eodem, Otto libertus, Adilbertus miles eius“5), — allein in diesem Falle

1) Vgl, oben S. 261 n. 1.

2) Dimitz, Geschichte der Edlinger im Sägor (Mitteilungen des historischen Vereines für Krain 1864 S. 16); Puntschart a. a. O. S. 198.

9) Hauptmann, Die Freileute S. 5 ff. (Carinthia I Jg. 100).

4) Mon. hist. duc. Car. II S. 83 n. 635 (1260), IV 1 S. 22 n. 1565 (1204), S. 533 n. 2691 (1258).

s) Puntschart a. a. O. S. 199 aus Zahn, Steir. UB. II n. 13 (c. 1170). 
hat Otto nur deshalb als Edler zu gelten, weil er unfreie Ritter unter sich hatte, also Lehens- und Grundherr war. Der libertus und libertinus im Sinne ron Edlinger war jedoch keines von beiden und gehörte daher nicht zu den Edlen. Sein lateinischer Name spielte vielmehr auf einen Niedrigeren als den Edelfreien an - nennen wir ihn den Gemeinfreien.

Zur Bezeichnung mittelalterlicher Standesklassen gab es also folgende lateinische Ausdrücke: liber-libertus-libertinus schillerten in der dreifachen Bedeutung von edel, gemeinfrei und minderfrei, nobilis dagegen hieß eindeutig edel, nicht gemeinfrei. Da nun Kases den gemeinfreien Baner bedeutete, so ist es jetzt wohl ohneweiters klar, daß man zwar libertus und libertinus als Übersetzung von Kas es ansehen darf, das deutsche Edlinger jedoch auf ein anderes Wort als Vorlage zurückführen muß.

Um diese verschollene Vorlage zu finden, knüpfen wir versuchsweise an den Widerspruch an, der zwischen Lesiak und unseren früheren Ausführungen $\mathrm{zu}$ bestehen scheint. Lessiak hält die Edlinger für turkotatarische Herrn der Alpenslawen ${ }^{1}$ ), wir aber möchten den Karantanerstaat als eine kroatische Gründung hinstellen 2).

Da die gesellschaftliche Stellung und die Bräuche der Herzogseinsetzung die Edlinger deutlich als ersten. Stand im Lande kennzeichnen, so ließe sich ein Ausgleich zwischen Lessiak und uns nur dadurcb vermitteln, daß man sagt, die Kroaten hätten den Karantanerstaat gegründet, um - Turkotataren zu dienen. Allein diese Auffassung spricht so sehr jedem geschichtlichen Sinne Hohn, dab man sich schließlich doch zu einem Entweder - Oder bequemen mußs: entweder waren die Edlinger wirklich Turkotataren, dann müssen alle unsre Ausführungen über die Kroaten in Karantanien rundweg abgelehnt werden, oder unsre Darstellung ist richtig, dann gab es für turkotatarische Herrn im freien Kurantanien keinen Platz. Für das Zweite, die ausschlaggebende Bedeutung der Kroaten, sprechen Ortsnamen und Quellen, für das Erste nur die turkotatarische Herkunft des Wortes Kases, eine Stütze, an sich sehr schwach, wenn man bedenkt, daß es noch niemand eingefallen ist zu behaupten, weil Vassall aus dem Keltischen stamme, seien die Vassallen des deutschen Mittelalters als eine keltische Kriegerkaste zu betrachten. Es wird daher mindestens gestattet sein, einmil vom Turkotatarentum der Edlinger abzusehen und sie probeweise für Kroaten zu halten. Bald wird man

1) Lessiak a. a. O. S. 92.

2) Vgl. oben S. 257 . 
gewahr, daß sich dadurch Vieles mühelos erklären ließe, was bisher in Dunkel gehüllt war. Man brauchte nicht mehr zu staunen, warum sich die Edlingersitze gerade dort häuften, wo Kroaten angesiedelt waren, man verstünde, warum die Huldigungsstätte im Kroatengau lag, wieso ein Edlinger dazukam, dem Herzog von Kärnten die Herrschaft zu übertragen: ja, man begriffe, weshalb der Herzog zur Einsetzungsfeier in Bauerntracht erschien. Die schlichte Tracht wäre eben mit ein Zeichen, daß sich einst in Kärnten kroatische Eroberer zu bäuerlichem Leben niedergelassen und dem Staate, den sie gegründet, einen ihresgleichen, mithin einen Baner, zum Fürsten gewählt hätten.

Unter solchen Umständen kann man nicht mehr achtlos an Gebräuchen vorübergehen, die bis in die neueste Zeit im alten Kernlande der Kroaten, Dalmatien, in Übung waren und die gerade in ihrem wesentlichen Inhalt mit der Kärntner Herzogseinsetzung übereinstimmten. Denn auf dem klassischsten Boden der kroatischen Geschichte, in der Nähe der längst verfallenen Königsstadt Bihač wählten die Dörfler von Staro Selo noch bis ins 19. Jahrhundert aus ihrer Mitte einen ,kralj“, einen Bauernkönig, führten ihn darauf zur Krönung auf den Hügel von Bihać und ließen sich von ihm schwören, daß er ein gerechter Richter sein werde. Witwen und Waisen beschützen wolle ${ }^{1}$ ). Sollte man diese auffallende Übereinstimmung, das Bauernfürstentum, hier wie dort wirklich anders erklären, als durch den einfachen Hinweis auf jene zweite Übereinstimmung, daß eben hier und dort Kroaten wohnten? Der letzte Rest von Argwohn gegen die Ableitung der karantanischen Edlinger aus kroatischen Eroberern aber schwindet, wenn man sieht, daß sich unter dieser Voraussetzung auch das Rätsel der Entstehung des Namens Edlinger löst. Denn "plemeniti ljudi“ d. i. Edlinger, nannten sich in Dalmatien die Angehörigen des herrschenden Stammes ${ }^{2}$ ) und Edlinger hießen die Herren wiederum auch in Kärnten. Die dritte, wohl überzengendste Übereinstimmung ist damit gefunden.

Der Name Edlinger muß daher in Kärnten so entstanden sein, dab im Gegensatze zum Karantaner, der als Awarenknecht seine neuen Herrn mit dem turkotatarischen Lehnwort Kases begrüßte, der Deutsche ihren Titel wörtlich übersetzte und sie Edlinger nannte. Kroate und

1) Milinović, Hrvatske uspomene u Dalmaciji (Vienac 18ð3, S. 219 f.). Kržaniǒ und Barač, V koljevci hrvatske porjesnice S. $51 \mathrm{f}$. - Vgl. auch Die österreichisch-ungarische Monarchie Bd. Dalmatien S. 162-164.

2) Klaić, Hrvatska plemena od XII. do XVI. stoljeća. Rad jugoslavenske akademije. Bd. 130, S. 13 ff. - Račlii, Hrvatskia prije XII. vieka (Rad jugoslav.akad. 57, S. 134). 
Edlinger waren ursprünglich dasselbe. Erst mit der Zeit verwischte sich diese Beziehung, da auch andere, selbst Deutsche, in den Edlingerrang aufsteigen konnten ${ }^{1}$ ) und außerdem das an Zahl schwache kroatische Herrenvolk in den slowenisehen Massen aufging. Mit ihm verschwand aber auch das "plemeniti ljudi“, es erstickte in dem viel gebräuchlicheren Kases. Nur in "Edlinger" klang noch Jahrhunderte später das kroatische Urwort nach, frei lich ohne daß sich die Deutschen dessen noch bewußt gewesen wären. Denn was sie bewog, gedankenlos von unedlen "Edlingern" zu reden, war einzig und allein die abstumpfende Macht der Überlieferung; wo di ese fehlte, wo ihnen, wie im Lateinischen, die Wahl des Wortes noch freistand, hatten sie für den Edlinger nur die Bezeichnung ge meinfrei-libertus übrig.

Man kann diese Erörterungen nicht beschließen, ohne eines überraschenden Gegenstückes in Ostrußland zu gedenken. Wie man im neven "Akademischen Wörterbuch der russischen Sprache" unter dem Titel „knjaz" nachlesen kann und wie mir Herr Prof. Nachtigall auf Grund eigener Erfahrung bestätigt, wird nämlich der Wolgatatar noch heute von den Russen "knjaz" (Fürst) genannt, obwohl er seinem Berufe nach nur Bauer, Händler, wenn nicht gar bloß Fuhrmann oder Hausierer ist. Ein schwacher Schimmer jener glanzvollen Tage, da seine Vorfahren als Herren in Rußland schalteten, liegt eben noch heute auf ihm, selbst wenn er nur als Hausierer umherzieht. Ebenso wenig wie einst der Nachkomme der kroatischen Eroberer Kärntens, unterscheidet sich also heute der Tatar Ostrußlands wirtschaftlich von seinen Nachbarn und trotzdem hier wie dort dieselbe Erscheinung: um seiner ehemaligen Herrnstellung willen nannte man jenen "Edlinger", heißt dieser "Fürst".

An der wichtigen Rolle, welche die kroatischen Edlinger in der Entstehungsgeschichte des Ka rantanerstaates spielien, kann man nun anch die politische Ohnmacht des slowenischen Volkes ermessen. Denn man bedenke: 629 waren die Alpenslawen der awarischen Herrschaft ledig, 631 wurden sie im Auftrage Dagoberts schon von den Langobarden besiegt, zum Teil wahrstheinlich auch unterjocht, um 650 aber saßen bereits Kroaten unter ihnen und legteu ihnen den Grund zu staatlichem Leben und Selbständigkeit. Sucht man sich die Abfolge dieser Ereignisse zu deuten, so ist man fast überzeugt, die Slowenen hätten sich, un fähig ihre Freiheit aus eigener Kraft zu behaupten, die Kroaten als Schützer und Ordner ins Land gerufen, oder wenigstens willig bei sich aufgenommen, ähnlich wie später die

1) Zahn, Urkundenbuch f. Steiermark II S. 493. 
mösischen Slawen den Stamm der Bulgaren 1) oder die Russen abenteuernde Waräger zu Herrn annahmen. Politische, staatserhaltende Kraft war den Slowenen unter dem Druck der awarischen Herrschaft abhanden gekommen, erst die Einwanderung des politisch begabten kroatischen Kriegerstammes hat den Karantanern jene Unabhängigkeit verschafft, deren sie sich bis zu den großen Umwälzungen des 8. Jahrhunderts erfreuten.

IV. Die Begründung der bayrisch-fränkischen Herrschaft. Die Conversio erzählt im vierten Kapitel, um die Mitte des 8. Jahrhunderts hätten die Awaren neuerdings begonnen, Karantanien zu bedrängen. Auf das Hilfsgesuch des Slowenenfürsten Borut seien die Bayern herbeigeeilt und hätten die Awaren verjagt, dafür aber sich „die Karantaner und ihre Nachbaren (confines eorum)" unterworfen. Da man in confines die Krainer erblicken will ${ }^{2}$ ), diese jedoch, wie wir oben dargetan haben, bis dahin den Awaren untertan waren, so hätten wir den Sieg der Bayern als das Ende der Awarenherrschaft über Krain zu betrachten. Allein, wer sagt, daß confines richtig gedeutet ist? Man könnte das schon aus militärischen Gründen bezweifeln. Denn es ist doch wahrscheinlich, daß die Awaren nach ihrer Niederlage nicht über die südlichen Gebirge, sondern längs der Drau aus Kärnten geflohen seien. In diesem Falle stand ihnen die alte Römerstraße am linken Drauufer zur Verfügung. Wenn, was naheliegt, die siegreichen Bayern ihnen nachsetzten, so kamen diese daher nicht nach Krain, sondern nach Steiermark nördlich der Drau und es wäre dann sehr begreiflich, daß die Bayern bei dieser Gelegenheit die Slawen Mittelsteiermarks unter ihre BotmäBigkeit gebracht hätten.

Wirklich braucht man von Kapitel 4 der Conversio nur um wenige Zeilen zurückzugreifen, um diese Vermutung gerechtfertigt zu sehen. Dort staht nämlich: "Wir kommen jetzt darauf zu sprechen, wie die sogenannten Karantaner und ihre Nachbarn im heiligen Glauben unterrichtet und bekehrt worden sind " 3).

Wenn hier der Salzburger Schreiber ankündigt, er wolle erzählen, wie sein Bistum "die Karantaner und ihre Nachbarn" fürs Christentum gewonnen habe und wenn derselbe Schreiber gleich darauf unter dieser Übersehrift kurz berichtet, wie die Bayern vorher erst die "Karantaner und ihre Nachbarn" unterwerfen mußten, so ist daraus

1) Niederle, Slovanské starožitnosti II S. 407.

2) Kos a. a. O. S. 263 A. 3. - Niederle a. a. O. IL S. 343.

s) Conversio cap. 3 . 
doch nicht nur klar, daß beidemale mit confines dieselben Nachbarn gemeint sind, sondern auch, wo man sie zu suchen hat. Denn außer im engsten Karantanien, in Kärnten, haben Salzburger Glaubensboten nur in Steiermark und Unterpannonien nördlich der Drau gewirkt 1), nur hier können also die confines gewohnt haben. Daran zu zweifeln, ist umso weniger gestattet, als eine andere Stelle der Conversio in der Tat ausdrücklich auf die „Nachbarn der Karantaner nördlich der Drau bis zu ihrer Mündung in die Donau“ "2) binweist. Da aber Westungarn noch bis auf Karl den Großen den Awaren gehörte, so verengt sich das Gebiet, das die Bayern ihnen um 750 entrissen haben sollen, schließlich noch mehr und es bleibt für die damals befreiten "Nachbarn der Karantaner" nur ungefähr Mittelsteiermark übrig, d. h. mehr oder weniger ausschließlich der Dudlebengau.

Untersteiermark und Krain allerdings behielten die Awaren auch weiterhin in ihrem Besitze. Man darf das behaupten nicht etwa bloß im Vertrauen darauf, daß ein Gegenbeweis aus den Quellen unmöglich ist, sondern weil die Umstände, die Tassilos Sturz begleiteten, es in nicht mißverständlicher Weise bezeugen. Von fränkischer Seite erfährt man nämlich, daß damals die dem Bayernherzoge verbündeten Awaren in Friaul einfielen ${ }^{3}$ ). Da man dabei so wenig wie 610 und 663 vou einem Widerstande der Slowenen an der Sawe hört, obwohl der Weg die Awaren gerade durch deren Land geführt haben muß, so ist es nur ein Gebot folgerichtiger Quellenbehandlung, wenn man erklärt, auch 788 seien die Krainer den A waren noch untertänig gewesen. Diese Auffassung stützt sich übrigens auch auf andere kaum weniger starke Belege, so vor allem auf die Quellenberichte über den ersten Feldzug Karls des Großen gegen die Awaren. Darin heißt es, ,das Heer, das Pippin seinem Vater zur Unterstützung geschickt, sei in Illyrien eingerückt [und von dort nach Pannonien gezogen] und habe gleich dem Heere Karls alles mit Feuer und Schwert verheert" ${ }^{4}$ ). Dadurch sei es gelungen, „in jenen Gegenden die Grenzen zu sichern " 5 ).

1) Conversio cap. $5-8$. Mühlbacher, Regesten der Karolinger n. 461.

2) Conversio cap. 8. Dazu Pirchegger, Karantanien und Unterpannonien zur Karolingerzeit. Mitteilungen des Instituts für österreichische Geschichtsforschung 33. Bd., S. 296.

s) Annales Einhardi ad 788.

4) Annales Laureshamenses ad a. 791 .

b) Mon. Germ. Epist. IV 32 ep. 7 (Alcuin). 
Nach allem, was über den verkehrsgeographischen Zusammenhang Westungarns mit Oberitalien feststeht, kann unter Illyrien in dem Fall nur das Slowenenland an der Sawe zu verstehen sein. Nur in Feindesland aber „rückt man ein“. Hält man daher zu dieser auffälligen Ausdrucksweise wiederum die trüher erwähnte Nachricht, daß die Awaren 788 als Tassilos Rächer in Friaul oder, wie eine andere Quelle sagt 1), in Italien eingefallen seien, so ist es wohl nicht zu bezweifeln, wo fränkischer Boden aufhörte und Feindesland begann. Nur Italien war fränkisch, Illyrien, unser Krain noch awarisch.

Zu demselben Ergebnisse kommt man schließlich auch, wenn man die Nachrichten über die kirchliche Ordnung im neu unterworfenen Awarenlande sammelt. Aus ihnen erfährt man folgendes:

Als Erich von Friaul 795 durch einen kühnen Vorstoß gegen dis Theiß die awarische Macht vernichtet und den Hauptring erobert hatte, sandte Karl im Jahre darauf seinen Sohn Pippin von Italien mit einem Heere nach Ungarn, um die letzten Funken des Widerstandes auszutreten. $\mathrm{Da}$ aber Erich seine Arbeit so gründlich getan hatte, daß sich die Franken bei der endgiltigen Besitznahme keiner ernstlichen Hindernisse mehr versahen, so war es Karls Plan, bei dieser Gelegenheit auch sofort die kirchlichen Verhältnisse zu regeln, damit das Bekehrungswerk unverzüglich beginne. In erst?r Linie kamen dafür Ârno von Salzburg und der gafeierte Patriarch von Aquileia, Paulin, in Betracht. Alkuin wandte sich daher sogleich mit der Aufforderung an sie, in den neugewonnenen Gebieten das Christentum zu verbreiten 2). Weil jedoch Paulin zwei Briefe unbeantwortet ließ, mahnte ihn Alkuin in einem dritten Schreiben besonders eindringlich an seine Christenpflicht und stellte ihm vor, daß ,aller Augen auf ihn gerichtet seien, um zu sehen, was er tun werde". Denn "seine Weisheit, sein hohes Ansehen und außerdem noch die $\mathrm{N}$ ähe des Heidenlandes", all das scheine ihn für diese Aufgabe geradezu vorherbestimmt zu haben ${ }^{3}$ ).

In dər Tat ließ sich Paulin dadurch bewegen, mit Arno in Pippins Gefolge nach Ungarn zu gehen. Dort vereinbarten beide Kirchenfürsten in gemeinsamer Beratung mit anderen Bischöfen die allgemeineı Grundsätze, nach denen sie die Bekehrung durchführen wollten ${ }^{4}$, dann zogen sie unter dem Schutze des Heeres wieder heim,

1) Mon. Germ. Epist. IV 528 n. 20 (Karl der Große an Fastrada).

2) Mon. Germ. Epist. IV 143 ep. 99 und 153 ep. 107.

3) Mon. Germ. Epist. IV 143 ep. 99.

4) Giannoni, Paulinus II., Patriarch von Aquileia S. 43. - Jaffé, Bibliotheca rerum Germanicarum VI S. 311-318. 
unterwegs aber, so heißt es in der Conversio, gab Pippin an Arno Unterpannonien zwischen Raab, Donau und Drau zur Mission ${ }^{1}$ ).

Nach der bisherigen Ansicht hätte damit Salzburg alles erhalten, was durch den siegreichen Feldzug Erichs dem fränkischen Reiche einverleibt worden war. Da es jedoch sicher ist, daß man gerade Paulin besonders bestürmt hatte, an der Bekehrung mitzuwirken, and er diesem Drängen schließlich auch nachgegeben hatte, so bliebe nichts übrig als zu glauben, man hätte ihn zuerst unter großen Versprechungen nach Ungarn gelockt, dann aber mit leeren Händen wieder zurückgeschickt. Allein das widerspricht durchaus der Rolle, die Paulin am karolingischen Hofe spielte ${ }^{2}$ ). Es ist daher viel einfacher und richtiger, ohne Hintergedanken anzunehmen, daß auch er seinen Anteil an dem eben gewonnenen Awarenlande bekommen habe. Nur muß man dann dieses weiter fassen, als es bisher geschehen ist. Denn da Unterpannonien nördlich der Drau an Salzburg fiel, war in Ungarn für Aquileia überhaupt nichts mehr frei, d. h. das an Paulin gediehene Stück des Awarenlandes muß außerhalb Ungarns gelegen haben. Es gibt aber nur ein Gebiet, das Erich auf seinem Marsche von Friaul nach Pannonien unterworfen haben kann und das zugleich später tatsächlich unter der kirchlichen Hoheit von Aquileia erscheint: das ist das Land an der alten Römerstraße, Untersteier und Krain. Von diesen Gegenden durfte Alkuin mit Recht sagen, daß Paulin schon wegen ihrer Nähe berufen sei, sie zu bekehren.

Die Befreiung der Slowenen vom. awarischen Joche war also in drei Abschnitten exfolgt: zwischen 623 und 629 hatten die Karantaner, Samos Siege ausnützend, ihr Land von den Awaren gesäubert, um 750 entrissen dann diesen die Bayern Steiermark nördlich der Drau und 795 brach endlich Erich ihre Macht auch in Untersteier and Krain. Seither waren alle Alpenslawen unter fränkischer Herrschaft vereint.

\section{Die karolingische Ordnung.}

Durch die Vernichtung des awarischen Reiches hatte Karl der Große die Pflicht unternommen, für eine neue Ordnung der Dinge im Osten zu sorgen. Der Jahrhunderte alte Haß der Slawen gegen ihre awarischen Peiniger war durch die Siege der Franken zu blutigen Taten entfesselt worden und drohte, die Donauländer auf lange Zeit

1) Conversio cap. 6 .

2) Giannoni a. a. O. passim. 
zum Schauplatz wüster Kämpfe zu machen. Um dies nach Möglichkeit zu verhindern, wies Karl der Große den Resten der Awaren eigene Banngebiete an, wo sie unter sich nach ihrer Vätor Art leben sollten. So siedelte er den Kapkan Theodor mit seinen Leuten zwischen Petronell und Steinamanger an ${ }^{1}$ ). Allein es erging den Awaren wie den Indianern in den Reservationen Nordamerikas ${ }^{2}$ ). Der Kolonistenstrom machte an der Grenze ihrer Weidegründe nicht Halt und wenn sie sich auch zuweilen in verzweifelten Aufständen gegen die bayrischslawischen Einwanderer erhoben ${ }^{3}$ ), ändern konnten sie ihr Schicksal nicht mehr, die alte Nomadenherrlichkeit war vorbei.

$\mathrm{Da} B$ sich aber diese Entwicklung ohne nachbaltige innere Wirren vollzog, die raubgierigen Nachbarn den Anlaß zu Einfällen hätten liefern können, das war der straffen Markenverfassung Karls des Großen zu danken. Leider sind über sie die Quellen so verschwiegen, daß seit jeher den verschiedensten Vermutungen Tür und Tor offen stand. Man erkannte wohl, daß Karl das weite Gebiet zwischen Friaul und der Donau in zwei Verwaltungssprengel zerschlagen und den einen dem Grenzgrafen an der Donau, den anderen dem von Friaul zugeteilt hatte, aher wie die Grenze verlaufen sein mag, darüber gingen die Meinungen wirr durcheinander. Dümmler glaubte, der Friauler habe ganz Karantanien und Unterpannonien in seiner Obhut gehabt, andere dagegen nahmen den Lauf der Drau als Grenze der beiden Amtsbezirke an 4). Dieser Ansicht schloß sich jüngst auch Pirchegger an. Sein Verdienst ist es, endgiltig dargetan zu haben, daß keine der Marken das ganze Volk der Karantaner beherbergte, sondern daß gerade ihr Land durch die karolingische Ordnung entzweigeschnitten wurde 5 ). Nur darf man nicht vergessen, daß mit der Teilung noch lange nicht die Drangrenze bewiesen ist. Dafür bringt Pirchegger nur eineu Beleg es fragt sich, ob er genügt.

Während der Kämpfe der Franken gegen Liudewit, den Fürsten des kroatischen Zwischenstromlandes, unterwarfen sich, wie die fränkischen Reichsannalen melden, dem Markgrafen Balderich von Friaul die Krainer und ein Teil der Karantaner, der zu Liudewit abgefallen war ${ }^{6}$ ). Pirchegger erblickt in diesen Karantanern untersteirische

1) Annales regni Francorum ad a. 805 .

2) Marquart, Osteuropäiische und ostasiatische Streifzüge S. XIX.

s) Annales regni Francorum ad a. 811.

4) Die verschiedenen Ansichten zusammengestellt bei Pirchegger a. a. O. S. 274 n. $\tilde{~}$.

s) Pirchegger a. a. 0. S. $275 \mathrm{ff}$.

в) Annales regni Francoru a ad a. 820 . 
Slowenen ${ }^{1}$ ) und glaubt daher, daß die Drau die Nordgrenze des Friauler Sprengels gewesen sei ${ }^{2}$ ). Indessen, verträgt sich dieser Schluß mit der Darstellung der Quelle? Wir lassen sie im Auszuge folgen: I. (Zum Jahre 819). "Als Balderich in das seiner Leitung unterstellte Land der Karantaner einmarschiert war, kam ihm dort das Heer Liudewits entgegen. Er griff es mit einer kleinen Schaar an, während es längs der Drau vorrückte, fügte ihm schwere Verluste zu und verjagte es aus jenem Lande“ 3).

II. (Zum Jahre 821). „Als der Winter vorüber war . . . schickte man drei Heere gegen Liudewit. Das eine zog von Italien über die Julischen Alpen, das andere durch Karantanien, das dritte durch Bayern und Oberpannonien ... Das mittlere, das durch Karantanien vordrang, war vom Glücke begünstigt, obwohl es an drei Orten mit den Feinden zusammenstieB. Denn, nachdem es die Gegner alle drei Male in die Flucht geschlagen und die Drau überschritten hatte, kam es rascher an den vereinbarten Sammelplatz als die beiden anderen Heere ... Als die Truppen zurückkehrten, unterwarfen sich Balderich die Nachbarn der Friauler, die Krainer, die an der Sawe wohnen. Dasselbe tat dann auch der Teil der Karantaner, der von uns zu Liudewit abgefallen war"4).

Nach I sprechen militärische Erwägungen gegen die Drau als Nordgrenze eines Karantaner Bezirkes, der zu Friaul gehört habe. Die Hauptstadt Liudewits war Sissek an der Kulpa 5); schon damals und nicht erst unter Braslav zu Ende des 9. Jahrhunderts muß also das Herz des Kroatenstaates der Flußwinkel zwischen der Sawe, Kulpa und Odra gewesen sein. Eilt man aber dann untersteirischen Bundesgenossen nach Nordwesten an die Drau zu Hilfe, wenn sie einen Angriff von $S$ üden über die Sawe erwarten? Das wäre um es durch einen Vergleich im Großen besser zu veranschaulichen ungefähr so, wie wenn uns in einem Kriege mit Italien Rumänien seine Truppen nach Schlesien schickte. Aus I ist daher die Draugrenze nicht zu beweisen. Ebenso wenig aber auch aus II. Denn die abtrünnigen Karantaner kämpften ja gegen die Franken nördlich der Drau. Schließlich muß man sich sagen, daß die Drau als Grenze geradezu unmöglich ist. Man braucht das nicht einmal damit zu begründen, daß in Kärnten doch die Karnischen Alpen und Karawanken

1) Pirchegger a. a. O. S. 275.

2) Ebenda S. $276 \mathrm{ff}$.

3) Annales regni Francorum ad a. 819 .

4) Ebenda ad a. 821 .

5) Ebenda ad a. 822 . 
die natürliche politische Scheide gegen die Mark Friaul gewesen wären. Entscheidend ist vielmehr folgendes: Von Borut, Gorazd, Hotimir und Waltunk empfängt man aus den Quellen immer den Eindruck, daß sie g a n z Karantanien beherrschten ${ }^{1}$ ). Dasselbe gilt für Pabo, den deutschen Nachfolger der slowenischen Volksherzoge, der etwa 844-861 regierte ${ }^{2}$ ). Nur in der Zwischenzeit sei also Karantanien in eine Nord- und Südhälfte zerfallen? Wie hätte aber dann vernünftiger Weise Kaiser Ludwig bei der Reichsteilung von 817 erklären können, er überlasse Ludwig unter anderm ,die Karantaner“3), wenn er doch zugleich durch denselben Vertrag die ganze Südhälfte Karantaniens Lothar zugewiesen haben soll? Außerdem ist noch etwas zu bedenken. Ohne Kampf waren die Slowenen beim Sturze Tassilos unter die fränkische Herrschaft geraten und so treu halfen sie fortan Karl in den Kämpfen gegen die Awaren, daß man ihnen ruhig ihre heimischen Herrscher beließ und später deren deutsche Nachfolger verhielt, sogar die altslowenische Einsetzungsfeier in aller Umständlichkeit über sich ergehen zu lassen. Während man so auf der einen Seite die Eigenliebe des slowenischen Volkes sorgfältig schonte, wird man sie doch nicht auf der anderen durch die Zertrümmerung seines Staates mutwillig verletzt haben. Kurzum, man begreift, nach der Drau kann das Ostland nicht aufgeteilt worden sein. Wie sonst?

„Als (827) die Bulgaren drauaufwärts zogen und die in Pannonien sitzenden Slawen mit Feuer und Schwert heimsuchten, vertrieben sie deren Fürsten und setzten an ihre Stelle bulgarische * 4). Im folgenden Jahre "wurde deswegen Herzog Balderich von Friaul abgesetzt, da wegen seiner Untätigkeit das Heer der Bulgaren Oberpannonien (richtig: Unterpannonien) ungestraft verwüstet hatte“ ${ }^{5}$ ).

Daß sich die Bulgaren bei ihrer Plünderung auf das rechte Drauufer beschränkt hätten, ist nicht anzunehmen. Aber selbst in diesem Falle hätte der Vorwurf der Untätigkeit mindestens ebenso den Grenzgrafen an der Donau getroffen, wenn sein Gebiet wirklich bis zur Drau gereicht hätte. So geht schon aus dieser Stelle hervor, daß sich die Mark Friaul noch über diesen Strom nach Westungarn erstreckt haben muß.

1) Conversio cap. $4 \mathrm{f}$.

2) Kämmel, Anfänge des deutschen Lebens in Österreich S. 215. - Pirchegger a. a. O. S. 277.

3) Mon. Germ, LL. I S. 198.

4) Annales regni Francorum ad a. 827 .

5) Ebenda ad a. 828 . 
Das ist auch sehr einleuchtend; einmal deshalb, weil Westungarn durch Erich und Pippin von Friaul aus unterworfen war und dann besonders darum, weil Karl der Große durch eine solche Gebietsordnung nur dem alten, uns wohlbekannten Naturzwang Rechnung trug, der schon seit Jahrhunderten Westungarn, Untersteiermark und Krain als feste geographische Einheit zusammengehalten hatte. Es erübrigt daher bloß, innerhalb dieses ausgedehnten Gebietes die Sitze jener Karantaner festzustellen, über die Markgraf Balderich von Friaul geherrscht haben soll. Das gelingt ohneweiters, weun man an der Hand der Conversio verfolgt, wie der Name Karantaner allmählich einen immer weiteren Sinn bekam.

Noch für die Zeit vor 750 zählte nämlich die Conversio die mittelsteirischen Slowenen nicht zu den Karantanern ${ }^{1}$ ); bei der Darstallung der Awarenkriege Karls des Großen dagegen faßte sie unter diesem Namen schon beide Gruppen der Alpenslawen zusammen 2). Sie durfte das mit gutem Grunde tun, weil in der Zwischenzeit infolge der Vereinigung Mittelsteiermarks mit Karantanien ${ }^{3}$ ) die Bezeichnung des Kerngebietes auch auf das Nebenland batte übergehen können. Da nun die Slowenen, die nach dem Ende des Awarenreiches das entvölkerte Westungarn besiedelten, offenbar aus diesem Neukarantanien einwanderten, so darf man sich nicht wundern, in dem Excerptum de Karentanis schließlich auch die westungarischen Slowenen Karantaner genannt zu sehen 4). Ihnen war eben ihr Name aus der alten Heimat in ihre neuen Sitze nachgefolgt. Die Untersteirer, zum mindesten die südlichen, hießen dagegen noch zu Liudewits Zeiten ganz anders. Sie waren bis dahin immer von den Karantanern getrennt gewesen, hatten dafür aber mit den Slowenen im heutigen Krain stets in innigster Beziehung gelebt 5). Die Folge davon war, daß man die Slowenen zu beiden Seiten der Sawe, d. h. in Krain und der südlichen Untersteiermark als ein Volk, als Krainer bezeichnete ${ }^{6}$ ). Wie Kunšič im

1) Conversio cap. 4: dazu die Bemerkungen über die Bedeutung von confines oben S. $266 \mathrm{f}$.

2) Ebenda cap. 3: quousque Franci ac Bagoarii cum Quarantanis continuis affligendo bellis eos (sc. Hunos) superaverunt. Quarantani sind hier ganz. allgemein die durch Tassilos Sturz unter fränkische Hoheit gekommenen Alpen. slawen, also die eigentlichen Karantaner und die noch von den Bayern dazugewonnenen Bewohner des steirischen Vorlandes im Osten von Kärnten; vgl. oben S. $266 \mathrm{f}$.

a) Vgl. oben S. 267.

4) Mon. Germ. SS. XI S. 15; dazu Pirchegger a. a. O. S. $298 \mathrm{f}$.

5) Vgl. oben S. $257 \mathrm{ff}$.

6) Annales regni Franc. ad a. 820: Carniolenses, qui circa Savum fluvium habitant. 
Zbornik Slovens'ne Matice I S. 97 mitteilt, schreibt Stanko Vraz noch 1838 an Šafařik, daß „schon gewöhnlich die Bewohner des Cillier Kreises Krajnci genannt werden “. Spuren dieses Sprachgebrauches lassen sich auch in alten untersteierischen Gegendnamen ohneweiteres erkennen. Denn Kraintsche östlich von Cilli, für das man im 15. Jahrhundert „in der Krain" sagte, Kraina nördlich von Rann und Krajina, südlich des Gonobitzer Berges ${ }^{1}$ ) gemahnen auch den Laien lebhaft genug an das bekannte Wort Chreina, das in den ältesten Urkunden als die slawische Bezeichnung für Krain auftritt 2). Wenn daher die fränkischen Reichsannalen melden, Balderich von Friaul habe ein Gebiet der Karantaner beherrscht, so bezieht sich das unmöglich auf Untersteiermark, sondern nur auf das slawische Kolonialland in Unterpannonien nördlich der Drau. Dann und nur dann ist es aber auch verständlich, warum Liudewit seinen karantanischen Bundesgenossen an die Drau zu Hilfe zog und diese die Franken gerade an der Drau erwarteten. Denn hier war die Südgrenze ihres Gebietes.

Die politische Ordnung im Osten war demnach die, daß Karantanien im engeren Sinne mit Oberpannonien verbunden war, während Unterpannonien nördlich der Drau, mit Krain durch Untersteier und allenfalls das westkroatische, von Slowenen bewohnte Zagorjaner Bergland zusammenhängend, unmittelbar Balderich gehorchte; und unter dessen Leitung stand auch Liudewits Staat in der weiten Mulde von Sissek.

Diese Auffassung gewinnt noch dadurch an Wert, daß man durch sie endlich auch die Entscheidung Karl des Großen von 811 über den Grenzstreit zwischen Aquileia und Salzburg richtig verstehen lernt. Wer immer bisher die Ansicht verfocht, die karolingischen Marken hätten sich an der Drau berührt, der ließ es sich nicht nehmen, mit einem Seitenblick auf die Urkunde von 811 zu betonen, daß sich im Frankenreiche öfter die politischen und kirchlichen Grenzen deckten. Wenn man daher aus Karls Verfügung erfahre, die Drau habe die Sprengel von Aquileia und Salzburg geschieden, so sei es nur methodisch anzunehmen, daß auch für die beiden Marken dieselbe Grenzlinie gegolten habe ${ }^{3}$ ). Da man nun aus der Conversio wußte, daß 796

1) Zahn, Ortsnamenbuch S. 112. - Trstenjak, Weriand de Graz (nach einer Besprechung Rutars in Zvon Bd. 5 S. 46.

2) Mon. Germ. Dipl. II S. 56 n. 47 und Font. rer. austr. Dipl. 31 S. 36 n. 37 (973): Carniola - quod vulgo Creina marcha appellatur.

3) Krones, Handbuch der Geschichte Österreichs 1, 274. Hasenöhrl, Deutschlands südöstliche Marken im 10., 11. und 12. Jahrh. Archiv für österreichische Geschichte 82, 533. Giannoni, Paulinus II., Patriarch von Aquileja S. 50. Werunsky, 
Pippin das eben eroberte Westungarn nördlich der Drau an Salzburg gegeben hatte ${ }^{1}$, so hielt man es für sehr wahrscheinlich, daß dieser Fluß schon damals als Grenze zwischen beiden Kirchen bestimmt worden sei und meinte, die etwas später erfolgte politische Ordnung habe sich infolgedessen hier nur an die schon vorhandene kirchliche Einteilung angelehnt. Das bedeutet aber für die Urkunde von 811, daß Karl der Große die Dïözesanbezirke Salzburgs und Aquileias nicht erst damals nach der Drau voneinander getrennt habe, sondern daß sein Crteil nur die alte Grenze gegenüber den Anfechtungen Aquileias feierlich habe bestätigen sollen. Im Eifer der Logik bedachte man jedoch nicht, daß gerade Karls Schiedspruch von 811 zu solchen Vermutungen am wenigsten Anlaß gibt.

Dort wird erzählt, daß Erzbischof Arno und der Nachfolger des Patriarchen Paulin von Aquileia, Ursus, vor Karl erschienen seien, um ihn entscheiden zu lassen, zu welcher Diözese Karantanien von rechtswegen gehöre. Ursus gab nämlich vor, ein altes Recht darauf zu haben, weil Karantanien vor dem Einbruch der Langobarden in Italien von Aquileia abhängig gewesen sei; Arno dagegen berief sich auf Verordnungen einiger Päpste, die jenes Land zu Salzburg geschlagen hätten. Dann heißt es wörtlich:

„Um die beiden Kirchenfürsten miteinander zu versöhnen und für alle Zukunft ihnen und ihren Nachfolgern jeden Grund zu Streitigkeiten zu nehmen, geruhten wir (Karl), nach gründlicher Behandlung ihres Falles die genannte Provinz Karantanien so unter sie zu teilen, daß die Drau, die mitten durch jenes Gebiet fließt, die Grenze zwischen beiden Sprengeln sei. - Zugleich . . . befehlen und gebieten wir, daß die hier anwesenden verehrungswürdigen Männer Maxentius, der erst kürzlich der Nachfolger des Patriarchen Ursus geworden ist, und Arno, der Erzbischof von Salzburg, in dieser Sache nie mehr eine Klage erheben, sondern zufrieden sein sollen mit dem Urteil, das wir nach Recht und Billigkeit... gefällt haben. Denn es erschien uns am richtigsten, jene Provinz, auf die sie beide angeblich Rechte besitzen, unter sie zu teilen, weil es uns peinlich gewesen wäre, die Ansprüche des einen oder andern als falsch und nichtig zu erklären“ 1).

Jeder Unbefangene muß schon aus dem Wortlaut der Stelle erkennen, daß erst durch diesen Erlaß die Drau in ganz Karantanien

Österreichische Reichs- und Rechtsgeschichte S. 265 n. 1. Kos, Gradivo 1. Bd., XXXV. Pirchegger a. a. O. S. $3 \mathrm{ff}$.

1) Conversio cap. 6.

2) Mon. Germ. Diplom. Karol. 1 n. 211. - Böhmer-Mühlbacher, Regesta imperii 2. Auf. 1 n. 461. 
als Grenze zwischen Salzburg und Aquileia festgelegt worden ist. Bisher kann sie es gar nicht gewesen sein. Denn angenommen, sie hätte dort schon vorher die Grenze gebildet, so hätte sich Karl durch seine Entscheidung 811 rückhaltlos auf die Szite Salzburgs gestellt und Aquileia offentlich ins Unrecht gesetzt. Gerade eine solche einseitige Stellungnahme aber wollte er ja nach seinen eigenen Worten um jeden Preis vermeiden und darum war für ihn ein Ausgleich der einzige Weg, der aus dəm Streit der beiden Kirchenfürsten zu einem dauernden Frieden führen konnte. Erinnert man sich, daß nach unseren Ausführungen Aquileia 796 aus der Awarenbeute Krain und Untersteiermark erhalten hatte, so wird es auch sofort klar, worin der Ausgleich bestand. Denn dann ergibt sich, daß Aquileia 811 a uf Kosten Salzburgs zu seinem bisherigen Missionsgebiet noch Südkärnten bekam. Nicht wenig dürfte zu diesem Ausgleich die Erwägung beigetragen haben, daß 796 durch die Verleibung des nördlichen Unterpannonien an Salzburg Aquileia eigentlich verkürzt worden war, weil es gestützt auf den Brauch, kirchliche und politische Grenzen zusammenfallen zu lassen, Diözesanrechte im ganzen Bereiche der Mark Friaul hätte beanspruchen können. Wenn es daher 811 Südkärnten empfing, so mag das eine wenn auch späte Entschädigung für den Verzicht auf Westungarn nördlich der Drau gewesen sein. Freilich war dadurch hier im Südosten des Karolingerreiches der Zusammenhang zwischen politischer und kirchlicher Einteilung vollständig zerstört. Denn wie man früher die Mark Friaul auf Salzburg und Aquileia aufgeteilt hatte, so war es jetzt mit der "Provinz" Karantanien geschehen.

\section{Die Reform Ludwigs des Frommen.}

Die politische Ordnung Karls des Großen überlebte den Tod ihres Schöpfers kaum 14 Jahre. Ihren Zweck, das christliche Abendland vor den Barbaren des Ostens, vor allem den Bulgaren, zu schützen, erfüllte sie nur, solange bloß die Donauländer der Wetterwinkel Europas waren. Diese Voraussetzung traf aber schon für das dritte Jahrzehnt des neunten Jahrhunderts nicht mehr ganz zu, da sich damals an der Adria im dalmatinischen Kroatenreich eine zweite Brutstätte politischer Gefahren gebildet hatte. Zwar hielt Ban Borna, vielleicht auch sein Nachfolger Ladislaus treu zu den Franken, aber wie unverläßlich so entlegene Vasallenstaaten waren, dafür hatte man an dem Herrscher Binnenkroatiens, an Liudewit, ein warnendes 
Beispiel 1). Was dieser getan, konnten über kurz oder lang anch die dalmatinischen Firoaten tun - und dann war die Sicherheit der italischen Küsten dahin.

Wir wissen nicht genau, ob es bereits in den zwanziger Jahren so weit kam, jedenfalls aber genügten schon die Piratenfahrten der süddalnatinischen Narentaner ${ }^{2}$ ), um Friaulern und Venetianern einen Vorgaschmack der Schrecken zu verschaffen, die ibrer harrten, wenn auch noch die seegewaltigen Kroaten an der ganzen Küste von Albona in Istrien bis zur Cetina in Dalmatien gegen sie losbrächen. Es i.st leicht zu verstehen, daß sich durch diese Entwicklung die politische Lage des Markgrafen von Friaul sehr verschlechterta. Denn nun sollte er nicht melr nur die Wacht an der Sawe gegen die Bulgaren halten, sondern auch die an der Adria gegen die Slawen der östlichen Küsten. Diese doppelte Aufgabe aber zersplitterte seine Kräfte und ließ befürchten, im entscheidenden Augenblicke könnte an der entscheidenden Stelle der Grenzschutz versagen. Dagegen konnte nur ein Mittel helfen und das war, die Aufgaben säuberlich zu trennen. Die Seepolizei in der Adria, die war naturgemäß von Italien aus zu besorgen; demselben Lande dazu aber noch die Grenzhut il Pannonien aufzubürden, war militärisch falsch, die übertrug man vielmehr am besten dem Grenzgrafen an der Donau. Bisher hatte er sich mit dem Markgrafen von Friuul in sie geteilt - wenn er nun die Grenzbut ganz in seine Hände nahm, so konntз das nur nützen, lag doch darin die sicherste Gewähr einer einheitlichen Binnenpolitik. Nicht politische Kurzsichtigkeit, sondern staatsmännische Klugheit trieb also dazu, sobald wie möglich, die karolingische Südmark wieder aufzulösen, damit nur Friaul und Istrien bei Italien bleibe, Krain, Untersteiermark und Unterpannonien nördlich der Drau dagegen mit den übrigen Alpenländern vereinigt werde.

Den Anlaß zu diesen Gebietsveränderungen gaben die Eraignisse von 827 und 828. Damals zogen nämlich die Bulgaren sengend und brennend in Unterpannonien umher, ohne von Balderich, dem Markgrafen von Friaul, gestört zu werden. Der Kaisex setzte ihn darauf wegen Untätigkeit $a b$ und zerschlug seine Mark in vier Grafschaften ${ }^{3}$ ). Zwei davon waren Friaul im engeren Sinne und Istrien, von den beiden anderen kann man vorläufig nur sagen, daß sie sich

1) Annales regni Francorum ad a. 818, 819, 820, 821.

2) Jireček, Geschichte der Serben I S. 196. - Marquart, Osteuropäische und ostasiatische Streifzüge S. $248 \mathrm{f}$.

3) Annales regni Francorum ad a. 827, 828. 
irgendwie in den Rest der alten Mark, Westungarn und Untersteiermark-Krain, geteilt baben müssen. Während aber jene bei Italien verblieben, ist es sicher, daß diese schon 828 ihrem westlichen Hinterland angegliedert wurden. Denn den Rachezng gegen die Bulgaren unternahm man nicht mehr von Italien aus, sondern dazu wurde noch 828 Ludwig von Bayern beordert ${ }^{1}$ ). Daß seither die ganze Ostgrenze dem Schutze des Herrn der Donauländer anvertraut war, zeigte sich auch zehn Jahre später im Kriege mit Ratimir, dem Fürsten von Sissek. Gegen seinen Vorgänger Liudewit war noch Balderich ron Friaul ausgezogen ${ }^{2}$ ), gegen Ratimir jedoch schickte man 838 Ratbod, den Grenzgrafen an der Donau ${ }^{3}$ ). Von einem italischen Heere war nich' mehr die Rede, Adria- und Donaupolitik waren jetzt reinlich geschieden, wie es der Größe ihrer Aufgabe entsprach.

Welche aber waren nun eigentlich die beiden Grafschaften, die nach der Auflösung der Mark Friaul in Untersteiermark-Krain und Westungarn eingerichtet wurden? Wenn man sich erinnert, daß nach den Awarenkriegen Unterpannonien nördlich der Drau von Karantanern besiedeit wurde, während südwestlich lavon zu beiden Seiten der Sawe die Krainer saßen, so scheint es unbedingt erwägenswert, ob nicht die Verwaltungsreform Ludwigs des Frommen an diese nationalen Verhältnisse angeknüpft und eine Grafschaft Westungarn neben einer an der Sawe geschaffin habe. Um dis zu entscheiden, geht man am besten von den Zuständen um 850 aus.

In Unterpannonien lebte damals der ans Nordungarn vertriebene Slawenfürst Pribina mit seinem Sohne Kozel. Durch die Gnade Ludwigs des Deutschen hatte er viele Güter zuerst zu Lehen, dann zu Eigen erhalten, auf deren verwilderten Koden er Scharen von deutschen nind slawischen Kolonisten berief ${ }^{4}$ ). Er war aber nicht etwa bloß Großgrundbesitzer, sondern zugleich auch Fürst mit einem eigenen „Dukat" 5). Das Herz dieses Fürstentums war die Gegend am Plattensee, wo die Moosburg lag; von hier reichten Pribinas Besitzungen bis nach „Ruginesuelt“, in der Grafschaft Dudleipa, nach Pettau, Fünfkirchen ${ }^{6}$ ) und an den Fluß „Valchau“ 7).

1) Annales Fuldenses. Mon. Germ. SS. I, 359.

2) Annales regni Francorum ad a. 819, 820.

s) Conversio cap. 10 .

4) Ebenda cap. 11; Böhmer-Mühlbacher, Regesta imperii 1 n. 1387, n. 138 dad.

s) Regesta imperii 1 n. 1442.

6) Vgl. n. 3-5, dazu: Bitterauf, Die Traditionen des Hochstiftes Freising 1 n. 887. - Pez, Thesaurus anecdotorum 1, 233. - Hauthaler, Salzburger Urkundenbuch 2, 35 b. - Regesta imperii 1 n. 1858. - Conversio cap. 11, 13.

7) Rigesta imperii 1 n. 1387. 
Über die Gegend, in die man den Valchau zu verlegen habe, war man lange im Unklaren. Oefele dachte an den Valpo, der bei Esseg in die Drau mündet 1); Pirchegger suchte dagegen den Valchau, Kos folgend ${ }^{2}$ ), in dem Flusse "Velih" in der Nähe des Plattensees oder in einem "Walchenau “ ${ }^{3}$ ), Niederle endlich erklärte ihn für die Vuka, die sich zwischen Drau und Sawe bei Vukovar in die Donau ergießt. Nach der Zusammenstellung der Namen, die sich seit dem zweiten Jahrhundert nach Christus für die Vuka finden, kann man allein Niederle recht geben 4). Er führt nämlich an: Ulca fluvius, Ulcus amnis, 030 ixos und bringt aus späteren ungarischen Quellen auch den Namen eines Ortes an demselben Flusse: castrum Wolkou, WuJckow, Walkow, Walko, villa Uulchoi, Uelchea.

Die sprachliche Erklärung von Valchau ist nun überaus leicht. Ch steht zunächst für $\mathrm{k}$ um des starken Hauches willen, mit dem man es aussprach: Valkau. A vor l erklärt sich aus der Schwierigkeit, das halbvokalische 1 von vlk (Wolf) schriftlich wiederzugeben. Die verschiedenen Auflösungsarten ersieht man aus der obigen Reihe. Entweder schlug man ein e vor (Uèlchea), ein u (Wùlckow), ein o (Wòlkov) oder ein a (Walkow); damit gewinnt man für das urkundliche Valchau die Form Vlkau.

Das au ist die Endung, die aus dem Hauptwort ein besitzanzeigendes Eigenschaftswort macht. Diese heißt eigentlich ov (Walkow), in der Aussprache aber lautet sie leicht wie au. Man braucht zum Vergleiche nur an die in Urbaren slowenischer Grundherrschaften überlieferte Ortsbezeichnung Fresa u für Brezovo zu denken. Das ergibt für "fluvius Valchau" fluvius Vlkov, oder einfach das Grundwort zu Vlkov: Vlka. Da aber das altslawische halbvokalische 1 im Serbischen zu u wird, so folgt daraus weiter: Valchau=Vuka.

Für den Umfang des unterpannonischen Fürstenlums würde dies lehren, daß Pribinas Herrschaft im Süden bis ins östliche kroatische Zwischenstromland, nach Sirmien, gereicht habe. Das wäre auch sehr begreiflich. Denn während Sirmien durch ungeheure Wälder und Sümpfe von der Westhälfte des kroatischen Tieflandes getrennt war, hing es enge wuit Ungarn zusammen, weil es dessen Völkern einen ebenso bequemen Weg nach Byzanz bot, wie Untersteiermark-Krain nach Italien. Die Ost- und Westhälfte des kroatischen Zwischenstrom-

1) Sitzungsberichte der phil.-hist. Klasse der kgl. bayrischen Akademie in München 1893 S. 298.

2) Kos, Gradivo 2, S. 109 Anm. 1.

s) A. a. O. S. 283.

4) Slovanské starožitnosti II, 1 ō0 und 366 . 
landes hatten daher Jahrhunderte lang jede ihr eigenes Schicksal: Die Römer verbanden Sirmien nicht mit dem Becken von Sissek, sondern schlossen es mit dem nördlich anstoßenden Ungarn am rechten Ufer der Donau zur Provinz Pannonia inferior zusammen. Die Hunnen berannten Sirmium im Osten, zerstörten Aquileia im Westen, die Awaren sicherten sich gleichfalls die Straßen nach Konstantinopel und an den Po und die Magyaren taten dasselbe, indem sie einerseits ihre Posten zwischen Donau und Sawe vorschoben, anderseits sich den Weg durch Untersteiermark-Krain nach Oberitalien erzwangen. Das Becken von Sissek aber lag zwischen den beiden Heerstraßen immer wie eine Verkehrswüste da. Es würde dahər nur ein Fortwirken uralter geographischer Einflüsse bedeuten, wenn in der Karolingerzeit wirklich wohl das Fürstentum Sissek nur in lockerer Abhängigkeit von den Franken gestanden hätte, Sirmien dagegen zusammen mit Unterpannonien nördlich der Dran uumittelbar mit ihrem Reiche vereint gewesen wäre.

Indes, war das zur Zeit Ludwigs des Deutschen noch politisch möglich? Erich von Friaul hatte allerdings die fränkische Herrschuft bis auf Sirmien ausgedehnt, allein 827 war doch dieses Gebiet den Bulgaren zugefallen und ein Rachezug der Franken im folgenden Jahre ${ }^{1}$ ) hatte so wenig Erfolg erzielt, daß die Bulgaren schon 829 von neuem fränkische Grenzlande brandschatzten ${ }^{2}$ ). Da Sirmium um 900 nachweislich ein bulgarisches Bistum war, so gilt es als ausgemacht, die Franken hätten 827 für immer den Donau-Sawewinkel vor den Bulgaren geräumt ${ }^{3}$ ). Dieser Ansicht zuliebe sagt man sogar dem Erzbischof von Sirmium, Method, nach, er babe nie in der Stadt, nach der er den Titel führte, seinen Sitz gehabt. Wir müßten daher den Valchau trotz des unaufechtbaren sprachlichen Zusammenhanges mit Vlka irgendwo nördlich der Drau suchen, denn südlich hätte Ludwig der Deutsche um 846 Pribina beim besten Willen nichts melır zu schenken gehabt.

Allein der Widerspruch zwischen der bisherigen Auffassung und unserer früher geäußerten löst sich, wenn man unbefangen den Gang der Ereignisse überdenkt, wie ihn die Quellen beschreiben: Ungefähr 836 war nach dem Zeugnis der Conversio Pribina aus Oberungarn vor dem Mährerfürsten Mojmir zu Ratbod, dem Grenzgrafen an der Donau geflohen. Da er sich aber bald mit diesem zerstritt, so entwich er zu

1) Annales Fuldenses. Mon. Germ. SS. 1, 359.

2) Ebenda 1, 360 .

s) Jireček, Geschichte der Serben 1, 194. 
den Bulgaren. Doch auch hier litt es ihn nicht lange und er begab sich daher zu Ratimir, dem Fürsten von Sissek. Als nun Ratbod im Auftrage Ludwigs des Deutschen Ratimirs Land eroberte, setzte Pribina über die Sawe und versöhnte sich durch Vermittlung des Grafen Salacho wieder mit Ratbod 1 ).

Sucht man sich nach diesen Angaben die politischen Verhältnisse der dreißiger Jahre zu vergegenwärtigen und die so gewonnene Einsicht durch andere Nachrichten zu vertiefen, so ergibt sich schließlich folgendes:

In Sissek herrschte zu jener Zeit Ratimir, der sich, glücklicher als sein Vorgänger Liudewit, wahrscheinlich schon 827 im Bunde mit den siegreichen Bulgaren die Unabhängigkeit von den Franken errungen hatte. Da sich die Bulgaren damals des bis dahin fränkischen Sirmien bemächtigt hatten ${ }^{2}$ ) und Ratimir so ihr unmittelbarer Nachbar geworden war, konnte Pribina um 838 ungefährdet aus Bulgarien zu ihm reisen, ohne befürchten zu müssen, unterwegs in Sirmien seinem Feinde Ratbod in die Arme zu laufen. Jedoch seines Bleibens war hier nicht lange, weil Ratimirs Land gerade um jene Zeit wieder von den Franken unterworfen wurde. Seither blieb es in dieser Untertänigkeit, ja später hielten seine Bewohner so treu zu den Karolingern, daß Fürst Braslaw von Arnulf sogar noch Unterpannonien nördlich der Drau zur Verwalting bekam ${ }^{3}$ ). Erst die Magyaren machten dann dem fränkischen Einfluß an der Sawe ein jähes Ende.

Beachtet man nun, daß in den dreißiger-vierziger Jahren Bulgarien unter Thronwirren und unglücklichen Kämpfen mit den Serben litt, und daß 845 eine bulgarische Gesandtschaft am fränkischen Hofe in Paderborn erschien ${ }^{4}$ ), so wird man unsere Auffassung gerechtfertigt finden, daß jener Valchau, an dem 846 Ludwig der Deutsche Pribina hundert Hufen verlieh, in der Tat die Vuka am rechten Ufer der Drau sei. Denn ohne Zweifel hatte Ratbod im Verfolge seines Sieges über Ratimir die unsicheren Verhältnisse in Bulgarien ausgenützt, um auch Sirmien wieder ans Karolingerreich zu bringen, von dem richtigen Gefühl geleitet, daß man der Kroaten von Sissek nur sicher sei, wenn man sie möglichst streng von ihren früheren Bundesgenossen, den Bulgaren, abschließe. Die Gesandtschaft von 845 bedeutet dann die

1) Conversio cap. 10.

2) Jireček, Geschichte der Serben 1, 194

3) Annales Fuldenses. Mon. Germ. SS. 1, 413.

4) Jireček, Geschichte der Bulgaren S. 149. - Dümmler, Geschichte des ostfränkischen Reiches 2. Aufl. 1, 285; Über die älteste Geschichte der Slawen in Dalmatien S. 396. 
Anerkennung der fränkischen Erfolge durch die Bulgaren und die Schenkung von 846 den Beginn einer weitausgreifenden Kolonisation unter der Leitung des treuen Pribina.

Daß an dieser Besiedelung auch Deutsche beteiligt waren, ist nicht nur mit Rücksicht auf die Rolle des Deutschtums in Unterpannonien als wahrscheinlich anzunehmen 1), sondern erhellt auch unmittelbar aus einem geographischen Eigennamen. Nordwestlich von Esseg liegt nämlich der Ort Valpovo. Die Endung des Wortes ist slawisch, nicht so der Stamm. Da der Wasserlauf, an den Valpovo liegt, heute Vuěica (Wolfsbach) heißt, so ist es sicher, daß das in Valpovo enthaltene Valpo das alte deutsche Wlpo oder Wulpo ist und das a wie in Valchau nur als Vorschlag vor das halbvokalische l geraten ist. Das Wortpaar Valchau-Valpo gehört nun zu jenen bedeutsamen geographischen Namenszwillingen, die sich dort finden, wo Deutsche in slawische Gebiete eingewandert sind. Zwei besonders auffallende Beispiele dafür kennt man aus der Umgebung von Graz. Unweit des Kroisbaches fließt dort der Ragnitzbach, dessen Name aus dem slowenischen rak (der Krebs, Krois) abgeleitet ista) und gleichfalls bei Graz erhebt sich der Geierkogel neben dem Schöckel, d. h. dem Sitze des sokols ${ }^{3}$ ). Beidemale ist es offenkundig, wie die Namengebung erfolgt war: die schütter wohnenden Slowenen hatton hier und dort einen Berg, einen Fluß in ihrer Sprache getauft und die Deutschen, die später einwanderten, hatten nicht den Ehrgeiz, bodenständige Namen durch Übersetzungen zu verdrängen, sondern bezeichneten damit lieber benachbarte Örtlichkeiten. Ähnlich muß es auch in Sirmien zugegangen sein: Deutsche wanderten über die Drau nach Sirmien, hörten dort von einem Flusse Vlka, unserem "Valchau" und übersetzten nnn diesen Namen mit Hilfe des gut deutschen Wlpo-Vàlpo, um damit den Nachbarfluß des „Valchau“ oder einen Ort an ihm zu bezeichnen.

Alles, was man über das Schicksal Sirmiens im 9. Jahrhundert erfährt, reimt sich somit auf unsere frühere Behauptung, daß das

1) Vgl. die Namen der Zeugen, die der Weihe der von Pribina erbauten Kirche zu Moosburg 850 beiwohnten: Conversio cap. 11.

2) Štrekelj, Prispevki $\mathbf{k}$ poznavanju slovenskih krajevnih imen po ncmškem Štajerju. Casopis za zgodorino in narodopisje I S. 80.

s) Für die Ableitung von Schökel aus sokol ein schlagendes Gegenstück in dem Dialektwort Scheckel, das ursprünglich die volkstümliche Umbildung für den Namen des Raubritters Sokol von Lamberg war: Güttenbergır, Österreichischer Schulbote 56, 465 . 
Fürstentum Pribinas und Kozels im Süden bis in den Donau-Sawewinkel gereicht habe 1). Nur wo die Westgrenze ihres Landes gewesen sei, ist noch nicht ohneweiters zu erkennen, da man uicht weiß, ob die Grafschaft Dudleipa zu Karantanien oder Unterpannonien gehört habe. Doch ist die Entscheidung dieser Frage durch die scharfsinnigen Bemerkungen Pircheggers über die Urkunde Ludwigs des Deutschen vom 20. November 860 bereits angebahnt 2). Sie erwähnt für Österreich, Westungarn, Steiermark und Kärnten etwa vierzig Orte, an denen Salzburg Besitzungen hatte. Die Aufzählung ist so dürr, daß einfach Name auf Name folgt; nur zwei „item“ zerlegen die Iiste in drei Abschnitte, die nach Pircheggers überzeugendem Beweis der Einteilung des karolingischen Ostens in Ober-, Unterpannonien und Karantanien entsprechen. Auf Grund dieser Entleckung suchte er nun die Grenze Unterpannoniens gegen Karantanien festzustellen und fand dabei folgendes:

Die Reihe der unterpannonischen Orte endet mit Nestelbach bei Ilz, dann kommen bereits in Karantanien die Raab, Tudleipin, Suln, ferner eine Kette von Orten bis Treffen im Bezirke von Villach, schließlich gelangt man über Obersteiermark wieder an die Raab zurück, wo als letzter Salzburger Besitz auf karantanischem Boden Langraben bei St. Ruprecht erscheint. Die Grenze zwischen Karantanien und Unterpannonien verlief daher unzweifelhaft zwischen St. Ruprecht und Nestelbach. Thre südliche Fortsetzung möchte man sich mit Hilfe der Angaben über Tudleipin zurechtlegen. Dies $ə$ r Ort, der nach sэinem Platze in der Urkunde von 860 zwischen Raab und Sulm, etwa an der Mur, zu suchen ist, war Mittelpunkt der gleichnamigen Grafschaft. Ihr gehörte zwar noch der mittelsteirische Gnasbach an, nicht aber der Lendvabach, der östlich von Gleichenberg entspringt und parallel der Mur in Westungarn flielit ${ }^{3}$ ). Die Grafschaft lag also ganz in der Mittelsteiermark und man sollte meinen, ihre Grenze und damit auch die Karantaniens gegen Unterpannonien habe sich zwischen den beiden Bächen hingezogen.

1) Daß Sirmien zu Unterpannonien geschlagen worden ist, ergebe sich nach Marquart übrigens auch aus folgender Stelle bei Porphyrogennetos: „Flußaufwärts liegt eine Stadt namens Sirmium, von Belgrad zwei Tagreisen entfernt; dort beginnt GroB-Mähren..., das die Magyaren besetzt haben und über das früher Swendoplok herrschte*. Marquart behauptet nämlich, Konstantin habe hier GrolsMähren mit Pribinas Reich verwechselt. Ist das wahr, so wäre diese Stelle allerdings auch ein Beweis dafür, daß Pribinas Fürstentum und damit das ostfränkische Reich sich bis nach Sirmien erstreckt haben.

2) Pirchegger a. a. O. S. $290 \mathrm{ff}$.

s) Ebenda S. 294. 
Merkwürdigerwesise will gerade Pirchegger davon nichts bören, da ihm die politische Zugehörigkeit von Dudleipa zu zweifelhaft ist. Nach einer Quellenmeldung war nämlich dort Kozel bagütərt, sein Vater Pribina hatte sogar in Dudleipa eine Kirche weihen lassen; da aber beide die Herren von Unterpannonien gewesen waren, so neigte man bisher der Ansicht zu, Dudleipa habe derselben Landschaft angehört, obwohl das in keiner Quelle staht. Es entspricht jedoch Pircheggers behutsamer Art, daß er um dieser landläufigen Annahme willen sogar der von ihm so glücklich ausgelegten Urkunde von 860 nicht unbedingte Beweiskraft zuspricht. Z/war meint er, die beiden Fürsten könnten auch außerhalb Pannoniens königliches Gut erhaltın haben, etwa im angrenzenden Karantanien. Dann wäre der Widerspruch zwischen den Nachrichten der Quellen nur scheinbar. Doch er kommt davon gleich wieder ab, denn so etwas „lasse sich wohl weder beweisen noch ableugnen".

Pirchegger treibt damit die Vorsicht zu weit. Wenn der Verfasser der Urkunde so bewandert war, daß er neunzehn karantaniscle Gegenden und Siedlungen genau in der ihrer Lage entsprechenden Ordnung anführt, wird er dann gerade von Dudleipin nicht einmal das Verwaltungsgebiet gekannt und den Ort aus Versehen in Karantanien anstatt Pannonien vermutat haben? Solche Gedanken widerlegen sich auch dadurch, daß ja Pannonien erst unter Karl dem Großen an die Deutschen fiel, Dudleipa dagegen schon von den Bayern zu Karuntanien geschlagen worden war, sodaß die Dudleberı in den Awarenkriegen bereits za den Karantanern zählten.

Wie soll man es aber dann verstıhen, daß Fürsten Unterpannoniens in Karantanien begütert waren? Pirchegger dachte, wie gesagt, an die Möglichkeit, der König habe ihnen eben auch außerhalb ihres Herrschaftsbereiches Besitzuagen verliehen. Doch warum? Königsland muß es in Pannonien selbst genug gegeben haben. Hier im eigen en Fürstentum Pribina etwas zu schenken anstatt in einer fremden Grafschaft, hätte gewiß den Vorteil gehabt, duß sich der Besitz hätte lejchter verwerten lassen. Die Sache wird daher anders zu erklären sein. Unterpannonien war ein wichtiges Grenzland des karolingischen Reiches. Aus dem Beispiel der Ostmark, die mit dem Traungau verbunden war, aber ersieht man, daß solche Gebietə zur Erhöhung ihrer Wehrfähigkeit als Marken eingerichtet und mit einer Grafschaft im Rücken als sicherem Hinterland ausgestattet waren. Ein ähnliches Verwaltungsgebilde war offenbar auch das Fürstentum Pribinas: Unterpannonien die Mark, Dudleipa dahinter die Grafschaft, durch die jene 
im Mutterlande verankert war. Der Besitz Pribinas in Dudleipa hat dann nichts mehr Wunderliches an sich; er war entweder ein Ausfluß königlicher Gnade oder geradezu das Amtsgut des Grafen.

Und nun zuriick zur Reform von 828! Von den vier Verwaltungssprengeln, in die man damals die karolingische Südmark zerschlug, kenneu wir jetzt die drei Marken Istrien, Friaul und Unterpannonien. Zieht man diese Bezirke vom Gebiete des alteu GroßFriaul ab, so engt sich der Raum, den die vierte Mark eingenommen haben kann, auf das Land zu beiden Seiten der Sawe ein. In der Tat wird gerade hier zwischen Friaul und Unterpannonien eine „marchia iuxta Sawam“ erwähnt, zu der nachweislich beide Ufer dieses Flusses in Üntersteier und Krain gehörten. Wiewohl sie erst für 895 urkundlich bezeugt ist 1 ), wird man doch ihre Entstehung nach den obigen Ausführungen unzweifelhaft in das Jahr 828 verlegen und nun auch in jenem Salacho, der um 838 als Graf an der Sawe gebot, den ersten geschichtlich bekannten Markgrafen dieses Gebietes erblicken ${ }^{2}$ ).

Die Reform Ludwigs des Frommen bestand also darin, daß er Balderichs Groß-Friaul in vier Marken auflöste und davon zwei, Istrien und Friaul im engeren Sinue, bei Italien beließ, Unterpannonien und die von den Krainern bewohnte Mark an der Sawe aber mit Karantanieu verband. Erst seither war die Voraussetzung gegeben, den Namen Karantaner auch auf die untersteirisch-krainischen Slowenen auszudehnen.

Unsere Darstellung ist zu Ende. In rasch wechselnden Bildern sind drei Jahrhunderte alpenslawischer Geschichte an uns vorübergezogen. Als Awarenknechte, sehen wir, traten die Alpenslawen in die Geschichte ein: nicht ein festgefügtes Volk, sondern, wie das Beispiel der Duljeben lehrt, ein loses Völkergemengsel, in zitternder Unterwürfigkeit gehalten durch Besatzungen seiner Herren. Erst nach 623 zu Samos Zeiten errangen die Alpenslawen ihre Freiheit, jedoch nicht auf lange. Denn schon um die Mitte desselben Jahrhunderts mußten die Karantaner wandernde Kroaten bei sich aufnehmen, die fortan als Edlinger unter ihrem Bauernfürsten das Land beherrschten, während die Slowenen an der Sawe neuerdings den Awaren erlagen, die mit

1) Jaksch, Mon. hist. duc. Car. 1, n. 3. - Dazu Pirchegger a. a. O. S. 297, 301.

2) Conversio cap. 10. - Schon von Pirchegger a. a. O. S. 279, 301 als wahrscheinlich angenommen. 
großem Geschick nach den Schlägen der samonischen Zeit ihre Vorherrschaft in den Donauländern wieder aufrichteten. Zwar unterwarfen sie sich nicht mehr die ganze Slawenwelt von den Sudeten bis hinab an den Balkan, sondern besetzten nur das österreichische Alpenvorland, dann die Landschaften an der pannonisch-friaulischen Straße und Sirmien, aber sie erzielten dabei doch einen vollen Erfolg. Denn der Besitz dieser Länder öffnete ihnen wieder den ersehnten Weg nach Byzanz, Italien und Bayern und legte zugleich an drei Stellen Breschen in den Slawenwall, sodaß den Awaren die Selbständigkeit Karantaniens und des Kroatenreiches an der Kulpa nicht mehr gefährlich werden konnte, waren doch diese Staaten durch die Umklammerung zu politischem Stilleben verurteilt.

Erst die Abkehr von dieser klugen Selbstbeschränkung in den vierziger Jahren des 8 . Jahrhunderts erschütterte von neuem die Macht der Awaren und gab den AnstoB zum Vormarsch des Deutschtums nach dem Osten. Denn die Bayern retteten nicht nur Borut um den Preis seiner Selbständigkeit vor den Angriffen der Awaren, sondern entrissen diesen auch noch das steirische Vorland Karantaniens nördlich der Drau. Und als später $791 \mathrm{Karl}$ der Große bis an die Raab vordrang und 795/96 Erich und Pippin in zwei Zïgen Krain, Untersteier und Westungarn eroberten, wurden die Awaren in "Reservationen" dem langsamen Untergang preisgegeben, die Alpenslawen aber in die christlich-germanische Welt einbezogen. Der fränkische Staat gah ihnen eine politische Ordnung, indem er ihnen entsprechend der alten, geographisch-geschichtlich bedingten Zweiteilung ihres Stammes. zwei Verwaltungsbezirke schuf: die Ostmark mit Karantanien, die Mark Friaul mit Krain, Untersteiermark, Unterpannonien nördlich der Drau und die fränkische Kirche nahm sie in ihre geistige Obhut, indem sie 796 dem alten karantanischen Sprengel Salzburgs Westungarn nördlich der Drau hinzufügte, Krain und Untersteiermark aber dem Patriarchate von Aquileia zuwies. Seitdem dann Karl der Große 811 in einem billigen Ausgleiche Südkärnten bis zur Drau un Aquileia verliehen hatte, wurde an den kirchlichen Verhältnissen nicht mehr gerüttelt. Wohl aber an den politischen. Denn unter dem frischem Eindrucke der Mißerfolge im Bulgarenkriege zerschlug man 828 GroßFriaul in vier kleine Marken, von denen Friaul und Istrien, bei Italien verbleibend, die Wacht an der Adria übernahmen, während die Marken an der Sawe und in Unterpannonien, unter der Oberleitung des Grenzgrafen an der Donau, das Reich vor den Barbaren des Ostens zu schützen hatten. Diese Reform bewährte sich auch so gut, daß man 
bald die Verluste von 828 wettmachen konnte. Der Graf der Ostmark beugte durch einen glücklichen Feldzug die Kroaten von Sissek wieder unter die fränkische Hoheit und eroberte im Anschluß daran sogar Sirmien von den Bulgaren zurück. Da man das neugewonnene Gebiet zu Unterpannonien schlug, war mit einem Male an der Donau ein Vorwerk fränkischer Reichsmacht geschaffen, stark genug, um den Kroatenstaat an der Kulpa vom slawischen Osten zu trennen und für eine friedliche Durchdringung vorzubereiten. Die unter Pribinas Augen sich vollziehende deutsche Einwanderung war bestimmt, diese Entwicklung zu beschleunigen. 